\title{
New Thai giant pill-millipede species, with new genetic barcoding data (Diplopoda, Sphaerotheriida, Zephroniidae)
}

\author{
SNEHA BHANSALI ${ }^{1,2} \&$ THOMAS WESENER ${ }^{1,3}$ \\ ${ }^{1}$ Zoological Research Museum Alexander Koenig, Leibniz Institute for the Analysis of Biodiversity Change (LIB), Adenauerallee 160, \\ D-53113 Bonn, Germany. \\ ${ }^{2}$ Corresponding author, ="sneharbhansali@gmail.com; ○https://orcid.org/0000-0002-5440-9958 \\ ${ }^{3}$ ”"T.Wesener@leibniz-zfmk.de; @ https://orcid.org/0000-0002-2028-3541
}

\begin{abstract}
Three new species of giant pill-millipedes, Sphaerobelum meridionalis Bhansali \& Wesener sp. nov., Zephronia chrysomallos Bhansali \& Wesener sp. nov. and Zephronia erawani Bhansali \& Wesener sp. nov. are described based on museum samples from Thailand. All three species are described in an integrative manner, combining light microscopy, scanning electron microscopy, CT scans and genetic barcoding. Genetic barcoding was successfully conducted for all holotypes of the new species. In addition, genetic barcoding data of four recently described Thai Zephronia species, Zephronia lannaensis Likhitrakarn \& Golovatch, 2021 in Likhitrakarn et al. 2021, Z. phrain Likhitrakarn \& Golovatch, 2021, Z. panhai Srisonchai et al. 2021 and Z. golovatchi Srisonchai et al. 2021, together with new locality records, were added to the dataset. Our dataset includes all published sequences of the family Zephroniidae, including all but one (Z. enghoffi Srisonchai et al., 2021) of the described species from Thailand, Laos and Cambodia. All new species are genetically distant from other Zephroniidae from Thailand and surrounding countries showing uncorrected p-distances of $>10 \%$. S. meridionalis sp. nov. is genetically and morphologically close to a recently described aberrant Sphaerobelum, S. aesculus Rosenmejer \& Wesener, 2021, as well as an unspecified specimen from Malaysia, and might represent a genus different from Sphaerobelum Verhoeff, 1924. Both new Zephronia species are geographically, morphologically and genetically close to Z. panhai, but differ from the latter by $>10 \%$ p-distance in the COI gene and numerous morphological characters. Virtual cybertypes of the holotype of Zephronia erawani $\mathbf{s p . ~ n o v . ~ a n d ~ o f ~ a ~ p a r a t y p e ~ o f ~ Z . ~ c h r y s o m a l l o s ~ s p . ~ n o v . ~}$ were created and made publicly accessible.
\end{abstract}

Key words: Cybertypes, CT Scan, DNA Barcoding, biodiversity, soil fauna

\section{Introduction}

The global diversity and distribution of one of the most species-rich groups of land arthropods in the world, the millipedes (class Diplopoda), remains understudied (Hoffman 1980; Shelley 2007; Brewer et al. 2012). These conspicuous soil arthropods are significant decomposers improving the quality of the soil in various vegetation types (Golovatch \& Kime 2009; Alagesan 2016). In its evergreen to deciduous forest, Thailand harbors a speciesrich millipede fauna (Enghoff 2005; Srisonchai et al. 2021), including giant pill-millipedes, Sphaerotheriida. Since the publication of the last catalog (Enghoff 2005) which mentions 105 species for Thailand, the millipede fauna of the country has received considerable attention in recent years, bringing the number of known species to ca. 240 from 48 genera (cf. Likhitrakarn et al. 2021). Of the five families representing Sphaerotheriida, Zephroniidae is the only family found in Southeast Asia (Wesener 2016). With only nine species of giant pill-millipedes known from Thailand, of which seven were described in 2021 (Rosenmejer et al. 2021; Likhitrakarn et al. 2021; Srisonchai et al. 2021), the number is still low compared to e.g. northeastern India, from which 22 species are known (Wesener 2015a). The Thai records contain species in the genus Sphaerobelum Verhoeff, 1924 and in the dominant and widely distributed genus Zephronia Gray, 1832. Hitherto, only two Sphaerobelum (S. truncatum Wongthamwanich et al., 2012; S. aesculus Rosenmejer \& Wesener, 2021) and seven Zephronia have been reported from Thailand (Z. siamensis Hirst, 1907; Z. lannaensis Likhitrakarn \& Golovatch, 2021; Z. phrain Likhitrakarn \& Golovatch, 2021; 
Z. viridisoma Rosenmejer \& Wesener, 2021 in Rosenmejer et al. 2021; Z. enghoffi; Z. golovatchi and Z. panhai all Srisonchai et al., 2021).

With eleven giant-pill millipede species documented from Laos since 2019 (Wesener 2019) and seven new species described from Thailand in 2021, it is clearly shown that many more species in SE Asia await discovery. With increased pressure on natural ecosystems due to rising anthropogenic changes, it has become ever more important to describe the unique fauna of biodiversity hotspots such as Thailand (Clements et al. 2006).

Recent studies have pointed out that genetic barcoding in combination with morphological characters is of great help in describing millipede species (e.g. Wesener 2015b). In this contribution we describe three new giant pillmillipede species from Thailand, adding molecular data to recent species descriptions, allowing genetic identification of almost all Thai, Laos, and Cambodian giant pill-millipede species. We describe all species integratively, combining morphology with genetic barcodes, and create a freely accessible cybertype for two of the new, not so easily identifiable Zephronia species.

\section{Material and methods}

\section{Abbreviations:}

CT-computer tomography

MHNG-Muséum d'histoire naturelle de la Ville de Genève, Geneva, Switzerland

SEM-scanning electron microscope

SMF-Senckenberg Museum Frankfurt, Germany

ZFMK-Zoological Research Museum A. Koenig, Leibniz Institute for Biodiversity Change (LIB), Bonn, Germany

NHMD - Zoological Museum, University of Copenhagen, Denmark

Map. The spatial information for the map was downloaded from GADM database v. 3.6 and the localities of the described species were mapped in QGis 3.16.14 Zanzibar (QGIS Development Team 2021).

Scanning electron microscopy. For scanning electron microscopy (SEM), the endotergum, left antennae, as well as for one species parts of the head were dissected. The samples were cleaned, and dehydrated via an ethanol series ( $2 \times 96 \%, 3 \times 100 \%)$ before being mounted on aluminum stubs. The samples were coated with gold for 240 seconds in a sputter coater. SEM images were taken using a Supra VR 300VP (Carl Zeiss AG) scanning electron microscope utilizing the Software SmartSEM V05.00, based at the ZFMK. After the study, dry coated SEM material was removed from stubs and returned to alcohol.

Dissecting, light microscopy, illustrations. Dissecting was done under a Zeiss Discovery V8 stereo microscope. Illustrations were produced by hand using pencil and paper, with a camera lucida mounted on the Zeiss Discovery V8 and later inked on tracing paper with Pigma Micron pens size 04 and 005. The scanned illustrations were edited in Adobe Photoshop before making plates on Adobe Illustrator. All terminology follows the recent literature (Wesener 2016).

Micro-computed tomography. Micro-computed tomography data were obtained for the male paratype of Zephronia chrysomallos sp. nov. and the male holotype of Zephronia erawani sp. nov. in $100 \%$ and $75 \%$ ethanol, respectively, at the ZFMK. Micro-CT data was obtained using a SkyScan 1272 (Bruker microCT, Kontich, Belgium) with the following scanning parameters: source voltage $=70 \mathrm{kV}$, source current $=142 \mu \mathrm{A}$, filter $=\mathrm{AL} 0.5 \mathrm{~mm}$, exposure $=1700 \mathrm{~ms}$, averaging $=5$, random movement $=15$, flat field correction $=\mathrm{ON}$, geometrical correction $=$ $\mathrm{ON}$. The parameter for pixel size $=6.51583,6.32032$; rotation of $180^{\circ}$ in rotation step $=0.200,0.150$ for Zephronia chrysomallos sp. nov. and Zephronia erawani sp. nov. respectively. Digital sections were reconstructed with NRecon ver. 1.7.0.4 (Bruker microCT, Kontich, Belgium) and the images were converted to 25bit grayscale images in Fiji Image J 1.52g (Schindelin et al. 2012). Volume rendering was performed in Drishti ver. 2.6 .3 (Limaye 2012). The reconstructed $\mu \mathrm{CT}$ Data, i.e., the cybertypes were deposited in Zenodo freely accessible under their own digital identifier (https://doi.org/10.5281/zenodo.5820654). The voucher specimens are stored at the ZFMK (ZFMK MYR8826) and NHMD (K56-9) for Zephronia chrysomallos sp. nov. and Zephronia erawani sp. nov., respectively.

DNA barcoding. In order to find relatives, match males to females, and investigate the intraspecific and interspecific COI distances of the species described here, a molecular genetic barcoding study (Hebert et al. 2003) was conducted. The DNA extraction, amplification, and sequencing of cytochrome c oxidase subunit I gene was 
done following the protocol similar to that employed in earlier studies (Sagorny \& Wesener 2017; Wesener 2019), using the degenerate primer pair HCO-JJ/LCO-JJ (HCOJJ AWACTTCVGGRTGVCCAAARAATCA / LCOJJ CHACWAAYCATAAAGATATYGG) (Astrin \& Stüben 2008). BLAST searches (Altschul et al. 1997) were performed to confirm sequence identities and to check for any contamination. Sequences were concatenated by hand or utilizing the software Seqman (DNASTAR Inc.). The whole dataset was translated into amino acids to ruleout the accidental amplification of pseudogenes. The 22 new sequences have been uploaded to GenBank under the accession codes OM509629- OM509650 (Table 1).

TABLE 1: Analyzed specimens, voucher and GenBank number. Specimens marked by an * have been newly sequenced. Abbreviations: $\mathbf{M H N G}=$ Muséum d'histoire naturelle de la ville de Genève, Geneva, Switzerland; NHMD = Natural History Museum of Denmark, University of Copenhagen; QVMAG = Queen Victoria Museum and Art Gallery, Tasmania, Australia; SMF = Senckenberg Museum Frankfurt, Germany; ZFMK = Zoological Research Museum Koenig, Bonn, Germany.

\begin{tabular}{|c|c|c|}
\hline Species & Voucher \# & GenBank \# \\
\hline Spirostreptida, Doratogonus sp. GG-2003 & unknown & AY288738 \\
\hline Glomerida, Glomeris marginata & ZFMK Myr009 & FJ409909 \\
\hline Sphaerotheriida, unknown family, Epicyliosoma sp. GB & unknown & AF370841 \\
\hline Sphaerotheriida, Procyliosomatidae, Procyliosoma leae & $\begin{array}{l}\text { QVMAG } \\
23: 45801\end{array}$ & FJ409910 \\
\hline Sphaerotheriida, Procyliosomatidae, Procyliosoma sp. & $\begin{array}{l}\text { QVMAG } \\
23: 25721\end{array}$ & FJ409911 \\
\hline Sphaerotheriida, Arthrosphaeridae, Arthrosphaera brandti & FMNH-INS 8650 & FJ409915 \\
\hline Sphaerotheriida, Zephroniidae sp. Ia & ZFMK Myr014 & FJ409912 \\
\hline Sphaerotheriida, Zephroniidae sp. Ib & ZFMK Myr015 & FJ409913 \\
\hline Sphaerotheriida, Zephroniidae sp. II (unknown genus) & lost & FJ409914 \\
\hline Sphaerotheriida, Zephroniidae, Sphaerobelum truncatum & $\begin{array}{l}\text { FMNH-INS } \\
72673\end{array}$ & JN885184 \\
\hline Sphaerotheriida, Zephroniidae, Zephronia siamensis & $\begin{array}{l}\text { FMNH-INS- } \\
72669\end{array}$ & JX486067 \\
\hline Sphaerotheriida, Zephroniidae, Zephronia ovalis & ZFMK Myr0832 & JX486068 \\
\hline Sphaerotheriida, Zephroniidae, Cryxus ovalis & ZFMK Myr0824 & JX486069 \\
\hline Sphaerotheriida, Zephroniidae, Zephronia dawydoffi & ZFMK Myr4504 & MK330971 \\
\hline Sphaerotheriida, Zephroniidae, Zephronia laotica & ZFMK Myr3502 & MK330977 \\
\hline Sphaerotheriida, Sphaerobelum bolavensis & MHNG LT-10/24 & MK330982 \\
\hline Sphaerotheriida, Zephroniidae, Sphaerobelum phouloei & NHMD00040257 & MK330974 \\
\hline Sphaerotheriida, Zephroniidae, Sphaerobelum denticulatum & MHNG LT-10/12 & MK330983 \\
\hline Sphaerotheriida, Zephroniidae, Sphaerobelum spinatum & ZMUC00040258 & MK330973 \\
\hline Sphaerotheriida, Zephroniidae, Sphaerobelum lachneeis & MHNG LT-10/12 & MK330982 \\
\hline Sphaerotheriida, Zephroniidae, Sphaerobelum peterjaegeri & SMF SD553 & MK330972 \\
\hline Sphaerotheriida, Zephroniidae, Sphaerobelum nigrum & SMF & MK330976 \\
\hline Sphaerotheriida, Zephroniidae, Sphaerobelum laoticum & SMF & MK330975 \\
\hline Sphaerotheriida Zephroniidae, Sphaerobelum schwendingeri & MHNG LT 10/03 & MK330978 \\
\hline Sphaerotheriida Zephroniidae, Sphaerobelum schwendingeri & SMF & MK330981 \\
\hline Sphaerotheriida, Zephroniidae, Sphaerobelum sp. L07 & NHMD00040261 & MK330979 \\
\hline Sphaerotheriida, Zephroniidae, Sphaerobelum sp. L10 & SMF & MK330980 \\
\hline Sphaerotheriida, Zephroniidae, Sphaerobelum aesculus M Holo & NHMD 621693 & MW898737 \\
\hline Sphaerotheriida, Zephroniidae, Sphaerobelum aesculus F & NHMD 621694 & MW898738 \\
\hline Sphaerotheriida, Zephroniidae, Zephronia sp., AowNoiTemple & NHMD K45 & MW898741 \\
\hline
\end{tabular}


TABLE 1. (Continued)

\begin{tabular}{|c|c|c|}
\hline Species & Voucher \# & GenBank \# \\
\hline Sphaerotheriida, Zephroniidae, Zephronia sp., AowNoiTemple & ZFMK MYR8822 & MW898742 \\
\hline Sphaerotheriida, Zephroniidae, Zephronia viridisoma Holotype & NHMD 621695 & MW898739 \\
\hline Sphaerotheriida, Zephroniidae Zephronia viridisoma F Paratype & ZFMK MYR8787 & MW898740 \\
\hline Sphaerotheriida, Zephroniidae, Zephronia lannaensis Chiang Mai* & ZFMK MYR3498 & OM509629 \\
\hline Sphaerotheriida, Zephroniidae, Zephronia lannaensis Chiang Mai* & ZFMK MYR3501 & OM509630 \\
\hline Sphaerotheriida, Zephroniidae, Zephronia lannaensis Chiang Mai* & ZFMK MYR4911 & OM509631 \\
\hline Sphaerotheriida, Zephroniidae, Zephronia lannaensis Doi Suthep - Mae & NHMD K57B & OM509632 \\
\hline \multicolumn{3}{|l|}{$\mathrm{Sa}^{*} \mathrm{~T}$} \\
\hline Sphaerotheriida, Zephroniidae, Zephronia lannaensis Doi Suthep* & MHNG 3B & OM509633 \\
\hline Sphaerotheriida, Zephroniidae, Zephronia phrain Chiang Mai* & ZFMK MYR3499 & OM509634 \\
\hline Sphaerotheriida, Zephroniidae, Zephronia phrain Chiang Mai* & MYR3500 & OM509635 \\
\hline Sphaerotheriida, Zephroniidae, Zephronia phrain Tham Houay Luk* & SMF & OM509636 \\
\hline Sphaerotheriida, Zephroniidae, Zephronia phrain Ma Lee* & SMF & OM509637 \\
\hline Sphaerotheriida, Zephroniidae, Zephronia phrain Tham Ngam* & SMF & OM509638 \\
\hline Sphaerotheriida, Zephroniidae, Zephronia phrain Chiang Dao* & ZFMK MYR4907 & OM509639 \\
\hline Sphaerotheriida, Zephroniidae, Zephronia phrain Doi Khuntan* & MHNG 5G & OM509640 \\
\hline Sphaerotheriida, Zephroniidae, Zephronia phrain Doi Chiang Dao* & MHNG 5I & OM509641 \\
\hline Sphaerotheriida, Zephroniidae, Zephronia phrain Ban Musoe* & NHMD K35 & OM509642 \\
\hline Sphaerotheriida, Zephroniidae, Zephronia panhai Ratchabourri R1* & ZFMK MYR8118 & OM509643 \\
\hline Sphaerotheriida, Zephroniidae, Zephronia panhai Tham Khao Bin* & MHNG 3A & OM509644 \\
\hline Sphaerotheriida, Zephroniidae, Zephronia panhai Ratchabourri R2* & ZFMK MYR8116 & OM509645 \\
\hline Sphaerotheriida, Zephroniidae, Zephronia golovatchi Route3052* & ZFMK MYR6262 & OM509646 \\
\hline Sphaerotheriida, Zephroniidae, Zephronia golovatchi Khao Yai* & NHMD K53 & OM509647 \\
\hline $\begin{array}{l}\text { Sphaerotheriida, Zephroniidae, Sphaerobelum meridionalis sp. nov. } \\
\text { holotype, Bang Lang* }\end{array}$ & MHNG 4B-2 & OM509648 \\
\hline $\begin{array}{l}\text { Sphaerotheriida, Zephroniidae, Zephronia chrysomallos sp. nov. } \\
\text { holotype* }\end{array}$ & ZFMK MYR8826 & OM509649 \\
\hline Sphaerotheriida, Zephroniidae, Zephronia erawani sp. nov. holotype* & NHMD K56x9 & OM509650 \\
\hline
\end{tabular}

Phylogenetic and distance analyses. The 22 new COI sequences were added to a dataset from a previous study, containing all published sequences of the Zephroniidae (at 06.2020) in addition to far- and near-outgroups (Rosenmejer et al. 2021). All sequences were aligned in Bioedit (Hall 1999). The final dataset contained 55 terminal and 674 base pairs (Table 1).

The number of base differences per site between sequences was calculated (p-distance analysis, see Supplemental material 1). The analysis involved 55 nucleotide sequences. Codon positions included were $1 \mathrm{st}+2 \mathrm{nd}+3 \mathrm{rd}$. All ambiguous positions were removed for each sequence pair. There were a total of 674 positions in the final dataset. Evolutionary analyses were conducted in MEGA6 (Tamura et al. 2013).

The best fitting substitution model for a maximum likelihood analysis was calculated with Modeltest (Tamura \& Nei 1993) as implemented in MEGA6. The best fitting model was the general time reversible (GTR)-Model (Tavaré $1986)$ with gamma distribution and invariant sites $(\mathrm{GTR}+\mathrm{G}+\mathrm{I})(\mathrm{lnL}=-11225.478$, Invariant $=0.389508456$, Gamma $=0.654092826, \mathrm{R}=2.741554897$; Freq A: 0.273683638, T: 0.333813575, C: 0.231304537, G: 0.160790497).

Phylogenetic analysis were performed in MEGA6 based on General Time Reversible model $(\mathrm{GTR}+\mathrm{G}+\mathrm{I})$. A species tree was constructed using maximum likelihood method with a gamma distribution of 5 categories. The tree with the highest $\log$ likelihood (-1125.9025) is shown in Fig. 1. An initial tree for the heuristic search was obtained automatically by applying Neighbor-joining and BioNj algorithms to a matrix of pairwise distance estimated using the Maximum Composite Likelihood (MLC) approach. Codon positions included were 1st $+2 \mathrm{nd}+3 \mathrm{rd}$. All positions with less than $5 \%$ site coverage were eliminated. The final dataset contained a total of 674 positions. The bootstrap 
consensus tree was calculated from 1000 replicates (Felsenstein 1985) in MEGA6 (Tamura et al. 2013). The obtained tree was edited in Adobe Illustrator CS2 with all bootstrap values $>70 \%$ as well as any nodes discussed in the text illustrated.

\section{Results}

Tree description and genetic distances between species. Interspecific distances in our dataset of Zephroniidae varied between 10.8-24\% (Sup. file 1). S. meridionalis sp. nov. shows the lowest genetic distance to Sphaerobelum aesculus, found $330 \mathrm{~km}$ apart (Fig. 2), with $17 \%$ divergence. Z. chrysomallos sp. nov. and Z. erawani sp. nov. show the lowest genetic distance to the three Zephronia panhai specimens, with a p-distance of $10.8 \%$ and $11.6 \%$ respectively. Both new species differ from one another by $11.9 \%$. Our genetic distance analysis discovered surprisingly high intraspecific distances in Z. phrain. While most populations differ by 3-5\%, one geographical satellite population from Ban Musoe differs by 6.4-7.6\%. In addition, our two populations tentatively identified as Z. golovatchi (one containing only female specimens) differ by $8.2 \%$ from one another (Fig. 1).

The gene tree might not be suitable to reconstruct deeper phylogenies, nevertheless are the order Sphaerotheriida (88\% bootstrap support) and the family Zephroniidae (51\%) recovered as monophyletic (Fig. 1). In the maximum likelihood tree, several high bootstrap support value of $100 \%$ were received for shallow nodes and a few deeper nodes received high support $(>/=70 \%$.).

Inside the family Zephroniidae, Cryxus was recovered in a basal position (albeit without statistical support) juxtaposed to all other Zephroniidae (Fig. 1). The next basal branch (statistically unsupported) unites a likely wrongly identified female Sphaerobelum from Laos, an unidentified Zephroniidae from Malaysia together with recently described Thai Zephronia which are morphologically aberrant (they have only one apical spine on the tarsi). The next split (statistically unsupported) divides the analyzed species into most Sphaerobelum and all other Zephronia specimens combined with Sphaerobelum nigrum. Inside Sphaerobelum, little resolution is achieved, but Sphaerobelum meridionalis sp. nov. is in a clade with an undetermined Zephroniidae from Malaysia and Sphaerobelum aesculus from Phuket with low branch support (41\%). Inside Zephronia, Z. phrain is sister taxon to Sphaerobelum nigrum from Laos, while the remaining species are in the Zephronia "sensu stricto" group with good statistical support (81\%). Here Zephronia lannaensis, Zephronia panhai, and Zephronia cf. golovatchi along with Z. chrysomallos sp. nov. and Z. erawani sp. nov. form a clade with high statistical support (99\%). Z. erawani sp. nov. was recovered as a sister-group to a well-supported clade (70\%) formed by Zephronia panhai and Z. chrysomallos sp. nov. (Fig. 1).

\section{Taxonomy}

\section{Class Diplopoda de Blainville in Gervais, 1844}

\section{Order Sphaerotheriida Brandt, 1833}

\section{Family Zephroniidae Gray, 1842}

Remarks. See Wesener (2016) for a catalogue of the family.

\section{Genus Sphaerobelum Verhoeff, 1924}

Remarks. For a recent revision and a key see Semenyuk et al. (2018), Wesener (2019), Semenyuk et al. (2020), Zhao et al. (2020), Rosenmejer et al. (2021).

Type species. Sphaerobelum clavigerum Verhoeff, 1924 (subsequently designated by Jeekel 1971: 28), from Vietnam.

Species included. 20 (including the one described below).

Distribution. Vietnam, Thailand, Laos, China. 


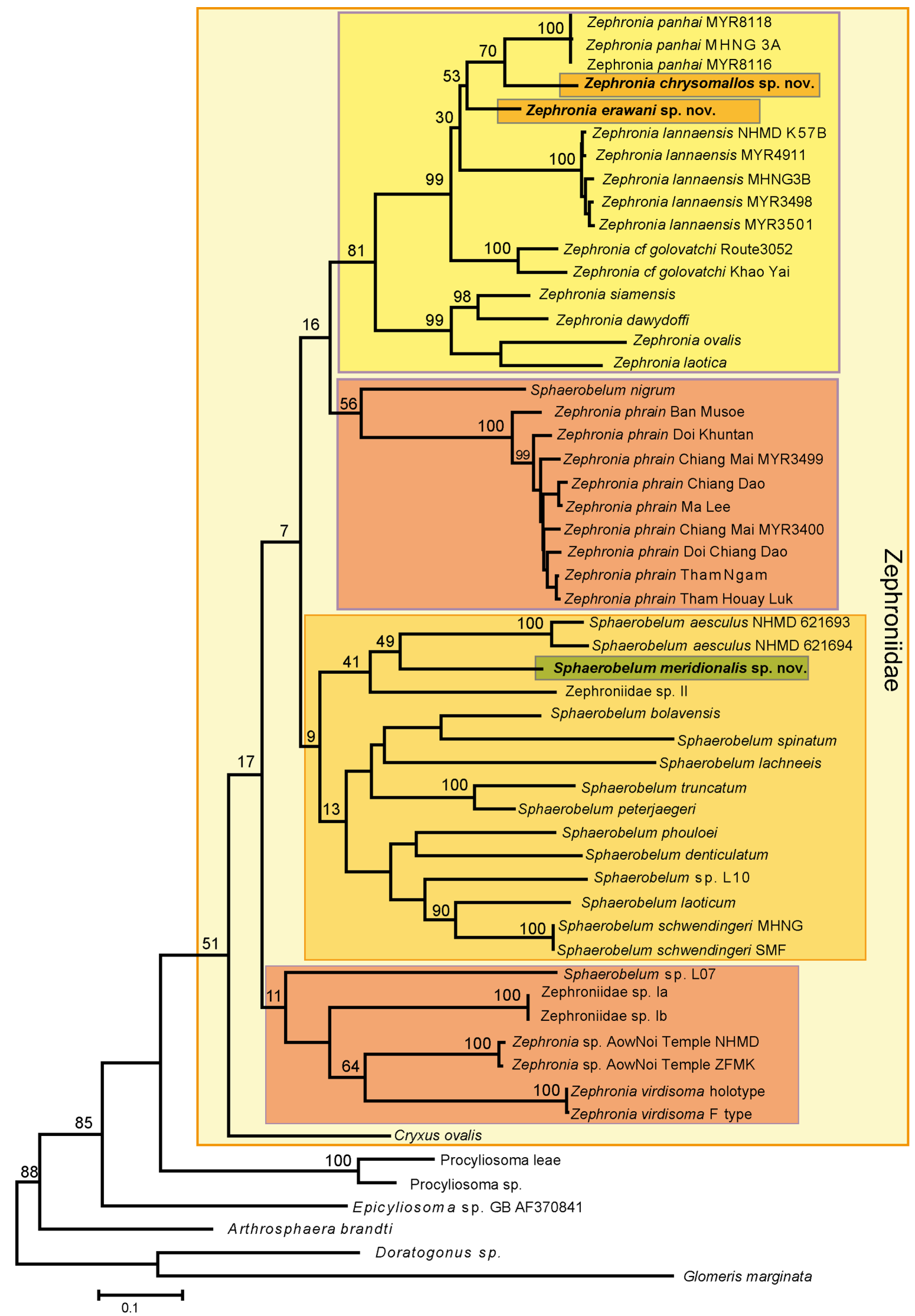

FIGURE 1. Maximum likelihood tree based on the COI sequence after 1000 bootstrap replicates analyzed with the General Time Reversible Model. Numbers on branches indicate bootstrap support. Codon positions included were $1 \mathrm{st}+2 \mathrm{nd}+3 \mathrm{rd}$. All positions with less than $5 \%$ site coverage were eliminated. The tree is drawn to scale, with branch length indicating genetic distance. Orange and green box represent new species of Zephronia and Sphaerobelum, respectively. 


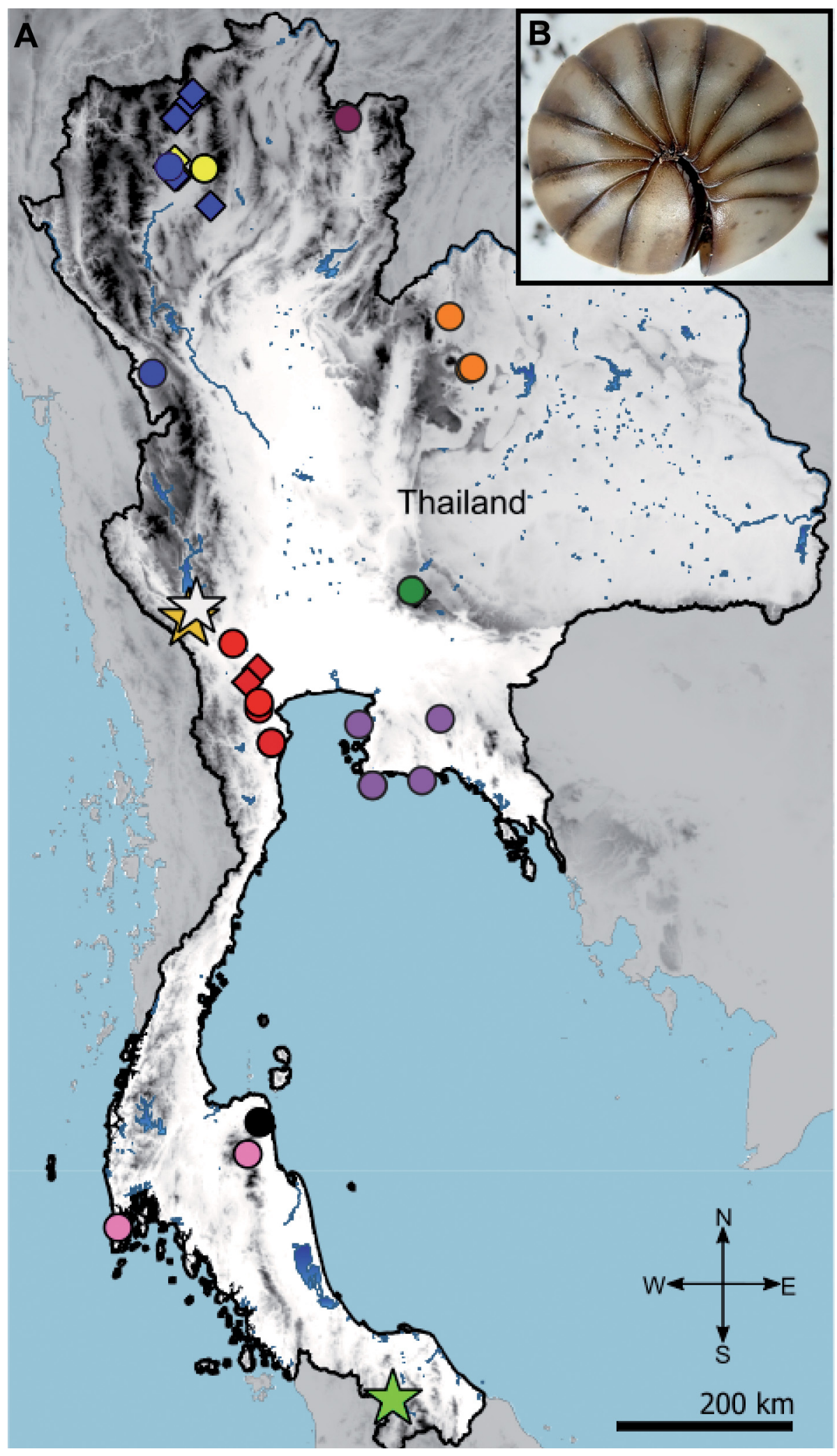

FIGURE 2. Map of Thailand with known distribution of Sphaerobelum spp. and Zephronia spp. Star represents new species. Diamonds represent new localities. Fluorescent Green $=S$. meridionalis Bhansali \& Wesener sp. nov.; Pink = S. aesculus; Brown $=S$. truncatum; Chrome yellow $=$ Z. chrysomallos Bhansali \& Wesener sp. nov.; White $=$ Z. erawani Bhansali \& Wesener sp. nov.; Black =Z. viridisoma; Red = Z. panhai; Dark green =Z. golovatchi; Purple =Z. siamensis; Orange $=Z$. enghoffi; Yellow $=Z$. lannaensis; Blue $=Z$. phrain. B. Habitus photograph of $Z$. chrysomallos Bhansali \& Wesener sp. nov., holotype $q$ (ZFMK MYR8826). 


\section{Sphaerobelum meridionalis Bhansali \& Wesener, new species}

Figures 2A, 3, 4, 5, 6A.

Diagnosis. Differs from all other species of the genus Sphaerobelum aside from $S$. aesculus in the shape of the posterior telopod, where there is a swelling at the tip of the immovable finger, but the swelling does not extend above the margin (Fig. 5B). Both species also share numerous other characteristics, such as general size and color, the glabrous, leather-like surface of the tergites and the shape of the anal shield, the low number of ventral spines on the legs, as well as the absence of apical spines on leg 3. S. meridionalis sp. nov. differs from S. aesculus in several characters, such as the presence of a distinct mesal process on the prefemur of midbody legs (Fig. 4B, arrow) (absent in S. aesculus), a mesal coxal process on the first coxae (Fig. 4A) (absent in S. aesculus), the telopoditomeres 3 and 4 of the anterior telopods being clearly separated (Fig. 4F) (being almost fused in S. aesculus) as well as some minor characters such as the lower number of ventral spines on the first tarsi (1 versus 4 in $S$. aesculus) and the slightly higher number of apical cones on the antenna (68-73 versus 52-56 in S. aesculus) (Fig. 3B). S. meridionalis sp. nov. differs from $S$. aesculus by an uncorrected p-distance on the COI gene of $17 \%$ (Sup. file 1).

Derivatio nominis. meridionalis, Latin for southern, adjective used as noun. Noun in apposition.

Material examined (total: 1 ふ)

Holotype

THAILAND: $1 \widehat{\jmath}$ (fragmented), MHNG 4B-2, Yala Province Yala, Bannang Sata District, Bang Lang National Park, near Than To Waterfall, [probably 6¹1'47.50"N, $101^{\circ} 9^{\prime} 50.90^{\prime \prime E}$ ], 150 m, 1.II.1991, leg. P. Schwendinger.

Description (based on holotype)

Size. Length $26.8 \mathrm{~mm}$. Width of thoracic shield $13.3 \mathrm{~mm}$, of widest segment $14.4 \mathrm{~mm}$. Height of thoracic shield $7.9 \mathrm{~mm}$, Height of highest segment (8) $8.8 \mathrm{~mm}$.

Color. Faded after 30 years in $75 \%$ ethanol. Head medium brown. Antenna pale light brown with traces of green and a brown border. Last antennomere distinctly light green. Legs pale brown, tarsi greenish. Tergites and anal shield medium brown with green color, ventral side light green. Posterior margin of tergites medium brown. Thoracic shield-like tergites but groove greenish.

Head. Number of ommatidia low, 61-65. Tömösváry organ located in antennal groove. Antennae short, reaching to center of head, antennomere lengths: $6>1>3=4>2=5$. Last antennomere apically slightly swollen (Fig. 3A), number of apical cones 73/68 (Fig. 3B).

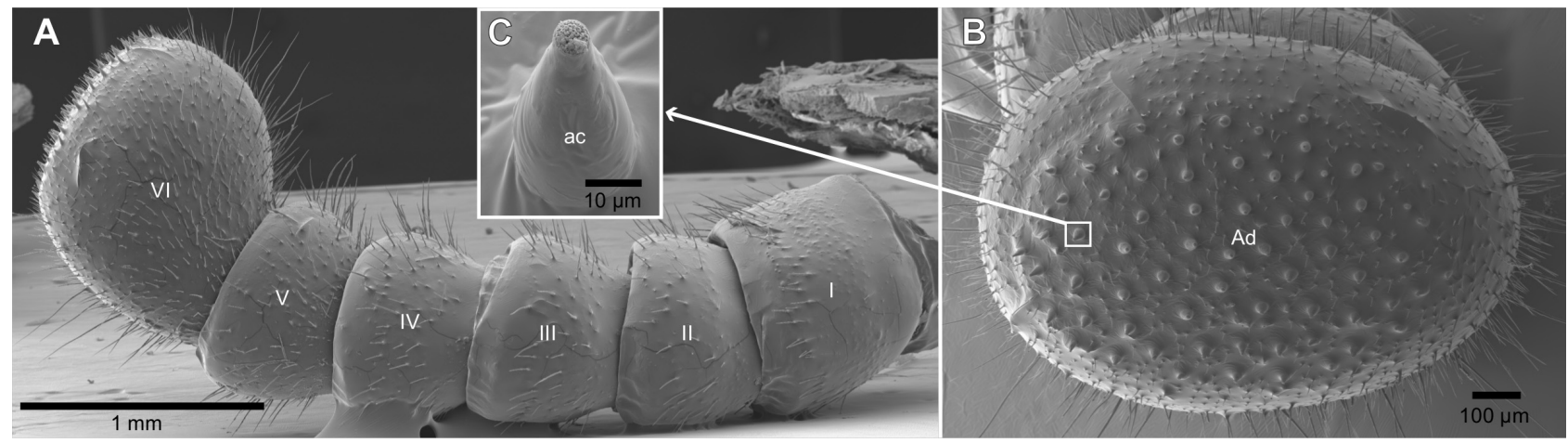

FIGURE 3. Sphaerobelum meridionalis Bhansali \& Wesener sp. nov., holotype đิ (MHNG 4B-2), scanning electron micrographs. A. Left antenna, lateral view. B. Right antenna, disc. C. Detail of apical cone. Abbreviations: ac = apical cone; $\mathrm{Ad}=$ antennal disc.

Mandible. Not dissected.

Gnathochilarium. Lingual lamella with numerous long setae. Palpi with sensory cones arranged in single field.

Collum. Setae distributed towards borders, more concentrated at lateral ends. Glabrous on posterior and median region.

Thoracic shield. Grooves wide and deep, with 5 or 6 sclerotized ledges along inner ridge. Surface like tergites.

Tergites. Paratergite tips on posterior half projecting backwards. Tergites glabrous with dull leather-like surface. 
Endotergum (Fig. 6A). With a regular flat margin. Outer zone with three rows of irregular marginal setae, not extending beyond posterior margin, but reaching $4 / 5$ of outer area. Middle section with a single row of distant, oval cuticular impressions. Distance between impressions twice the diameter. Inner area with numerous rows of setae, widely distributed, shorter than marginal setae.

First stigmatic plate (Fig. 4A). Large, larger than coxa, with a well-rounded apex.

Pleurites. Pleurite 1 weakly projecting posteriorly with a sharp apex. Pleurite 2 short with well-rounded apex, not projecting.

Legs. Ventral spines on leg $11 / 1$, on 2 2/2, on $34 / 4$. Apical spine absent on leg 3 . Three apical and 6 or 7 ventral spines on midbody legs (Fig. 4B). Inner margin of femur with up to 20 small teeth, but not excavated. Femur 1.7, tarsus 3.8 times longer than wide. Prefemur with conspicuous mesal process (Fig. 4B arrow). First coxae with conspicuous mesal process (Fig. 4A).

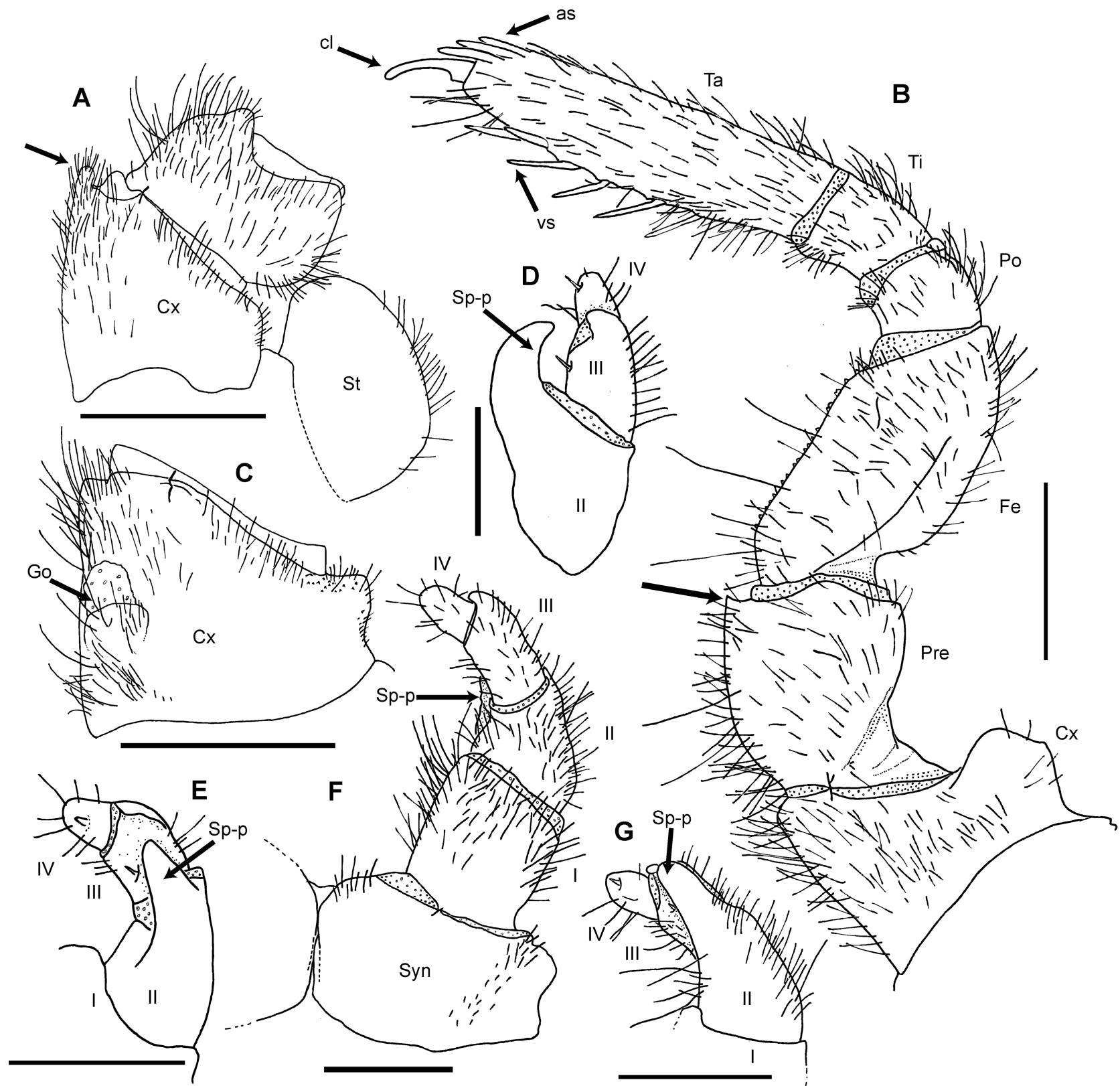

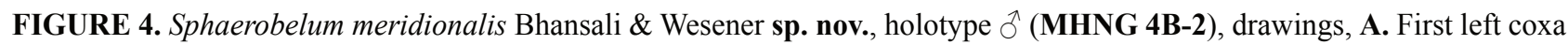
with stigmatic plate, posterior view, arrow points to mesal coxal process. B. Left leg 9, posterior view, arrow points to mesal process on prefemur. C. Second left coxa with gonopore, posterior view. D. Left anterior telopod, lateral view. E. Right anterior telopod, meso-posterior view. F. Right anterior telopod, anterior view. G. Right anterior telopod, posterior view. Abbreviations: as = apical spine; $\mathrm{cl}=$ claw $\mathrm{Cx}=$ coxa $; \mathrm{Fe}=$ femur; $\mathrm{Go}=$ gonopore; $\mathrm{Po}=$ postfemur; Pre = prefemur; $\mathrm{Sp}-\mathrm{p}=$ second podomere process $; \mathrm{St}=$ stigmatic plate; $\mathrm{Syn}=$ syncoxite $=$ tarsus; $\mathrm{Ti}=$ tibia; $\mathrm{vs}=$ ventral spines. Scale bars $=1 \mathrm{~mm}$. 


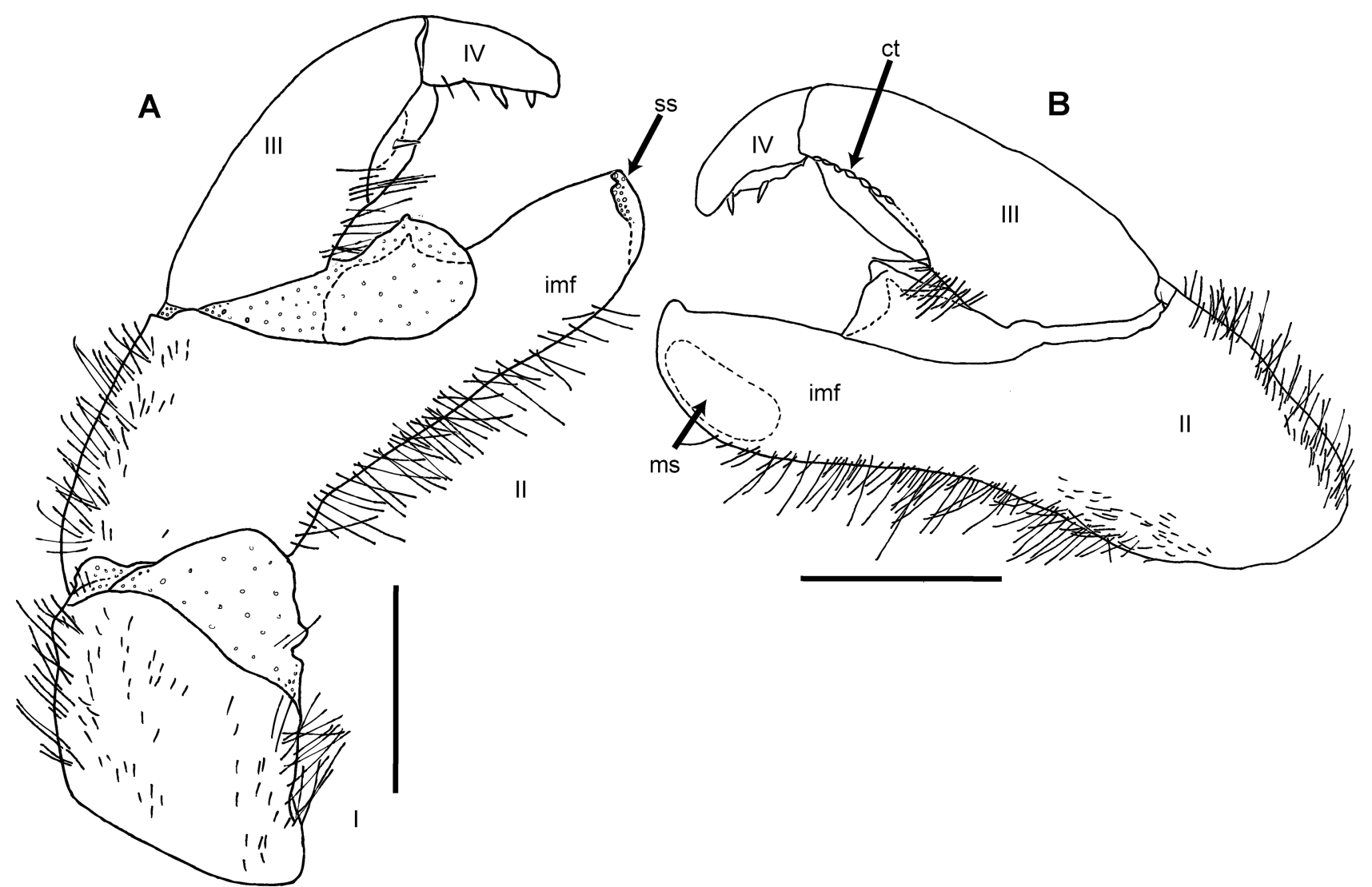

FIGURE 5. Sphaerobelum meridionalis Bhansali \& Wesener sp. nov., holotype $\widehat{\jmath}$ (MHNG 4B-2), drawings, A. Left posterior telopod, anterior view. B. Left posterior telopod, posterior view. Abbreviations: $\mathrm{ct}=$ crenulated teeth; imf $=$ immovable finger; $\mathrm{ms}=$ membranous spot; $\mathrm{ss}=$ sclerotized spot. Scale bars $=1 \mathrm{~mm}$.

Anal shield. Well-rounded and glabrous. Ventral side with single medium length locking carina, placed close to margin.

Male sexual characters. Gonopore (Fig. 4C) large, consisting of large membranous opening located directly at mesal margin of second coxa, covered posteriorly by a single semicircular sclerotized plate.

Anterior telopods (Figs 4D-G). Syncoxite with few setae. Podomere 1 rectangular 1.2 times longer than wide, more densely covered with setae in apical half than at basal margin, with longer setae medially, basal margin glabrous. Podomere 2 with wide process visible in anterior view, protruding to half-length of podomere 3 . Process curved, well-rounded, apically slightly tapering (Fig. 4D). Podomere 3 cylindrical, almost twice as long as wide, latero-apical process juxtaposed to process of podomere 2. One spine visible in lateral view. Podomere 4 clearly separated from podomere 3 , cylindrical, of half-length of podomere 3 , with one spine below apex visible in posterior and lateral view.

Posterior telopods (Fig. 5). Syncoxite inner horns (not drawn): well-rounded, apically tapering. Podomere 1 rectangular, as long as wide, with moderately long setae. Podomere 2 with a single, large triangular membranous lobe at base of immovable finger. Immovable finger wide, straight, slightly wider anteriorly and apex tapering towards movable finger in a small process. Process with sclerotized round spots in anterior view. Single large oval membranous spot visible in posterior view. Surface of finger glabrous except for margins. Podomere 3 circa 3 times longer than wide. Membranous ledge with a single spine, Posterior side with a row of 7 small crenulated teeth. Glabrous except for several long setae clustered at lower inner margin. Podomere 4 short, apically tapering, slightly curved towards immovable finger, ca. 2.5 times longer than wide. Membranous ledge and 2 spines present mesal margin. Glabrous.

\section{Distribution}

Only known from the area near the Than To Waterfall in the very south of Thailand (Fig. 2A). 

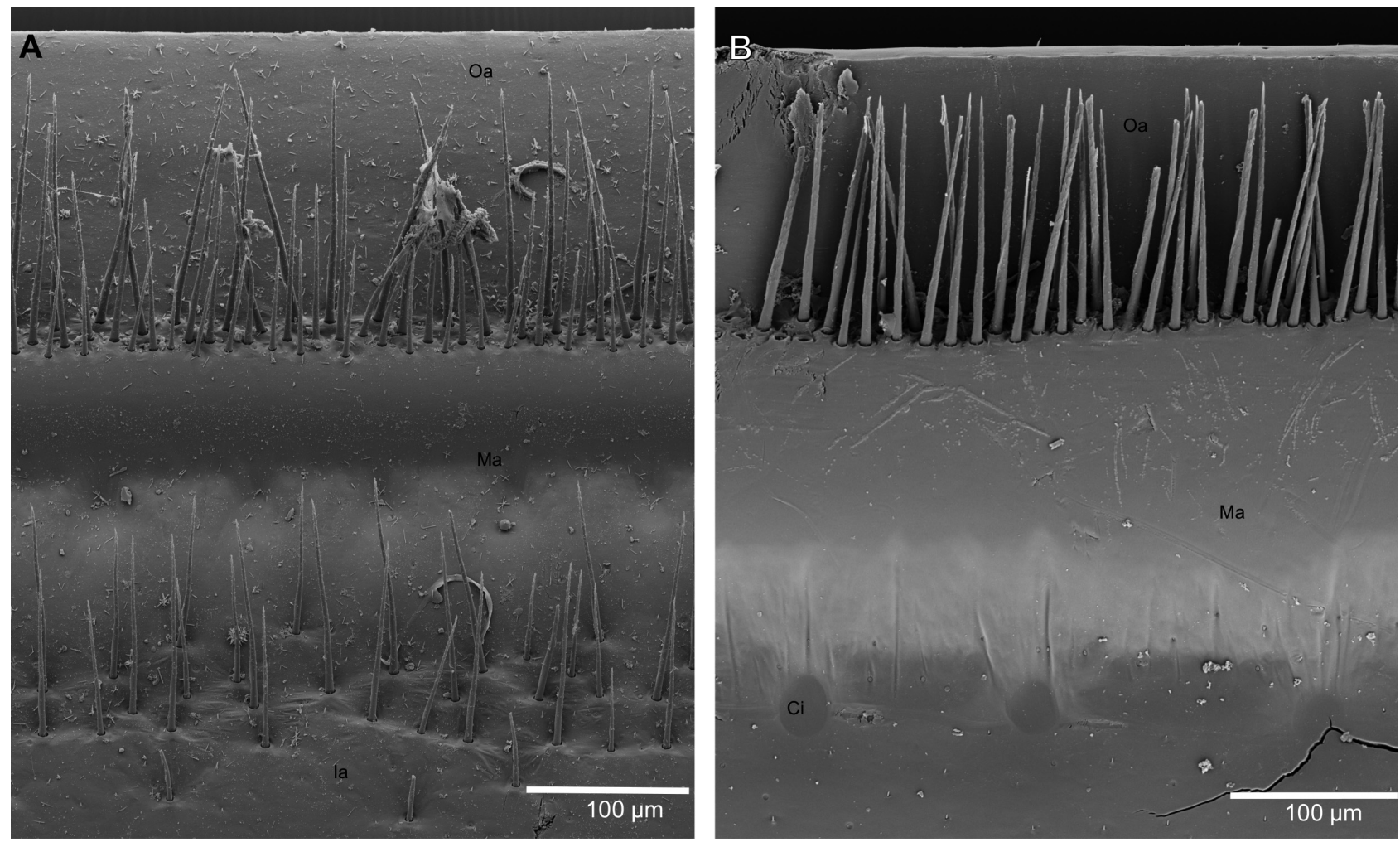

FIGURE 6. Endoterga of midbody tergites, scanning electron micrographs. A. Sphaerobelum meridionalis Bhansali \& Wesener sp. nov., holotype $\widehat{\jmath}$ (MHNG 4B-2). B. Zephronia chrysomallos Bhansali \& Wesener sp. nov., holotype $\widehat{\partial}$ (ZFMK MYR8826). Abbreviations: $\mathrm{Ci}=$ cuticular impression; $\mathrm{Ia}=$ inner area; $\mathrm{Ma}=$ middle area; $\mathrm{Oa}=$ outer area.

\section{Genus Zephronia Gray, 1832}

Type species. Zephronia ovalis Gray, 1832 (by monotypy).

Species included. 48, including the two described below (Wesener 2016a, 2019; Semenyuk et al. 2018, 2020; Likhitrakarn et al. 2021; Rosenmejer et al. 2021; Srisonchai et al. 2021).

Distribution. NE India, Nepal, Myanmar, with a few species also in other SE Asian countries.

\section{Zephronia chrysomallos Bhansali \& Wesener, new species}

Figures 2A-B, 6B, 7, 8, 9, 10, 11.

Diagnosis. The position of the organ of Tömösváry at the brim and not in the antennal groove identifies this species as a member of the Zephronia sensu stricto group, with which it also aligns weakly genetically (Fig. 1). The sensory cones on the palpi of the gnathochilarium are arranged in a single field, not in separate clusters (Fig. 8D) and the body is covered in a dense coat of golden setae like in several other Thai Zephronia. The greyish brown tergites color resembles those of $Z$. erawani sp. nov. and $Z$. panhai (Fig. 2B). The male second leg mesal coxal margin is not extended into a membranous process, a character shared only with Z. lannaensis and Z. panhai. Zephronia chrysomallos sp. nov. differs from Z. lannaensis in the color (grey versus brown), telopod characters as well as the endotergum. Z. chrysomallos sp. nov. differs from Z. panhai in being much larger in size (40 $\mathrm{mm}$ versus $20 \mathrm{~mm})$, the higher number of ventral spines on the walking legs (10-12 versus 7-9), the higher number of apical cones on the antenna (78-88 versus around 50), the higher number of rows of marginal bristles on the endotergum ( 3 versus 2 ) and the shape of the first pleurite, which is weakly extended and well-rounded in Z. chrysomallos sp. nov. but with a long sharp process in $Z$. panhai. Z. chrysomallos sp. nov. differs genetically in the COI barcoding fragment from $Z$. panhai by a p-distance of $10.8 \%$, from Z. erawani sp. nov. by a p-distance of $11.9 \%$ and from Z. lannaensis by $14.8-15.2 \%$ (Sup. file 1 ). 
Derivatio nominis. chrysomallos, Greek, meaning Golden Wool, and also the flying sheep ram Chrysomallos from Greek mythology, which was sacrificed to Zeus in order to obtain the famous Golden Fleece. Noun in apposition.

\section{Material examined (total:7 $\left.\widehat{\partial} \widehat{O}^{\Uparrow}\right)$}

Holotype

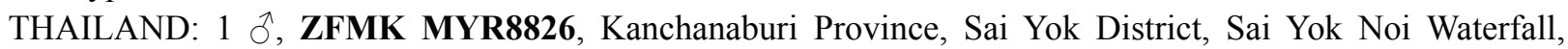
$14^{\circ} 14^{\prime} 12^{\prime \prime} \mathrm{N}, 9^{\circ} 03^{\prime} 46^{\prime \prime} \mathrm{E}, 150 \mathrm{~m}$.

\section{Paratypes}

THAILAND: 1 ๙, ZFMK MYR11366, CT scan voucher, same data as for holotype; 1 ๙ , ZFMK MYR11365, same data as for holotype.

\section{Other material}

THAILAND: 4 $\delta$ ठ , CUMZ, Kanchanaburi Province, Sai Yok District, Sai Yok Noi Waterfall (Khao Phang

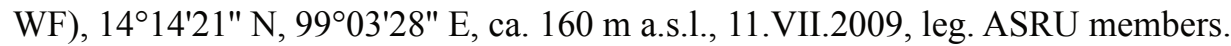

\section{Description (based on holotype)}

Size. Length: ca. $40 \mathrm{~mm}$. Width of thoracic shield $16.3 \mathrm{~mm}$, of widest segment (8th) $16.9 \mathrm{~mm}$. Height of thoracic shield $9.4 \mathrm{~mm}$, of highest segment (8th) $11.5 \mathrm{~mm}$.

Color (from living specimens). Head, collum and anterior margin of thoracic shield dark brown to black. Antenna dark brown, legs pale brown. Tergites and anal shield greyish-brown (fading to light brown in ethanol), darker towards posterior margin. Thoracic shield-like tergite with darker anterior and posterior margins. (Fig. 2B).

Head (Fig. 7D). Number of ommatidia more than 90. Tömösváry organ placed on rim of antennal groove. Antennae (Fig. 7A-D) short, axe-shaped (Fig. 8A-C), not reaching to center of head (Fig. 7C), antennomere lengths: $6>1>5=4=3=2$. Antennomere 1 basally with scales (Fig. $8 \mathrm{~A}$ ). Antennomere 6 apically wide, and flattened, axe-shaped, with 78/88 apical cones (Fig. 8C).

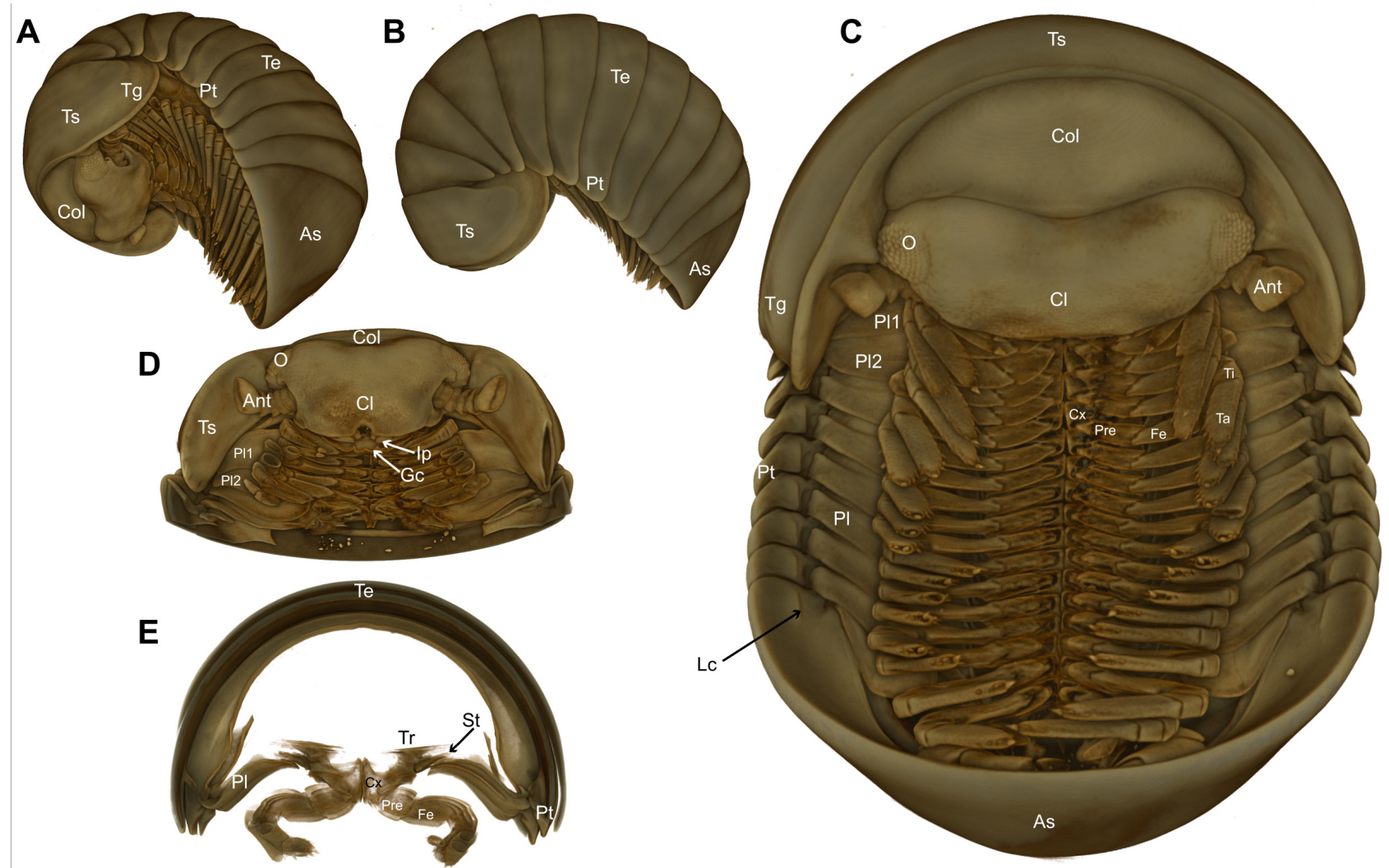

FIGURE 7. Zephronia chrysomallos Bhansali \& Wesener sp. nov., paratype $ð$ (ZFMK MYR11366), volume rendering based on micro-computed tomography. A. Habitus, lateral view. B. Habitus, ventro-lateral view. C. Habitus, ventral view. D. Habitus, anterior view. E. Body-ring architecture, cross section trough midbody-ring. Abbreviations: Ant = Antennae; As = anal shield; $\mathrm{Cl}=$ clypeus; $\mathrm{Col}=$ collum; $\mathrm{Cx}=$ coxa $; \mathrm{Fe}=$ femur; $\mathrm{Gc}=$ gnathochilarium; $\mathrm{Go}=$ gonopore $\mathrm{Ip}=$ inner palpi; $\mathrm{Lc}=$ locking carina; $\mathrm{O}=$ ommatidia $\mathrm{Pl}=$ pleurite; $\mathrm{Pl}=$ pleurite $1 ; \mathrm{Pl}=$ pleurite $2 ; \mathrm{Pre}=$ prefemur; $\mathrm{Pt}=$ paratergite $; \mathrm{St}=$ stigmatic plate $; \mathrm{Ta}=$ tarsus; $\mathrm{Te}=$ tergite $\mathrm{Tg}=$ thoracic shield groove; $\mathrm{Ti}=$ tibia; $\mathrm{Tr}=$ tracheal apodeme; $\mathrm{Ts}=$ thoracic shield. Not to scale. 

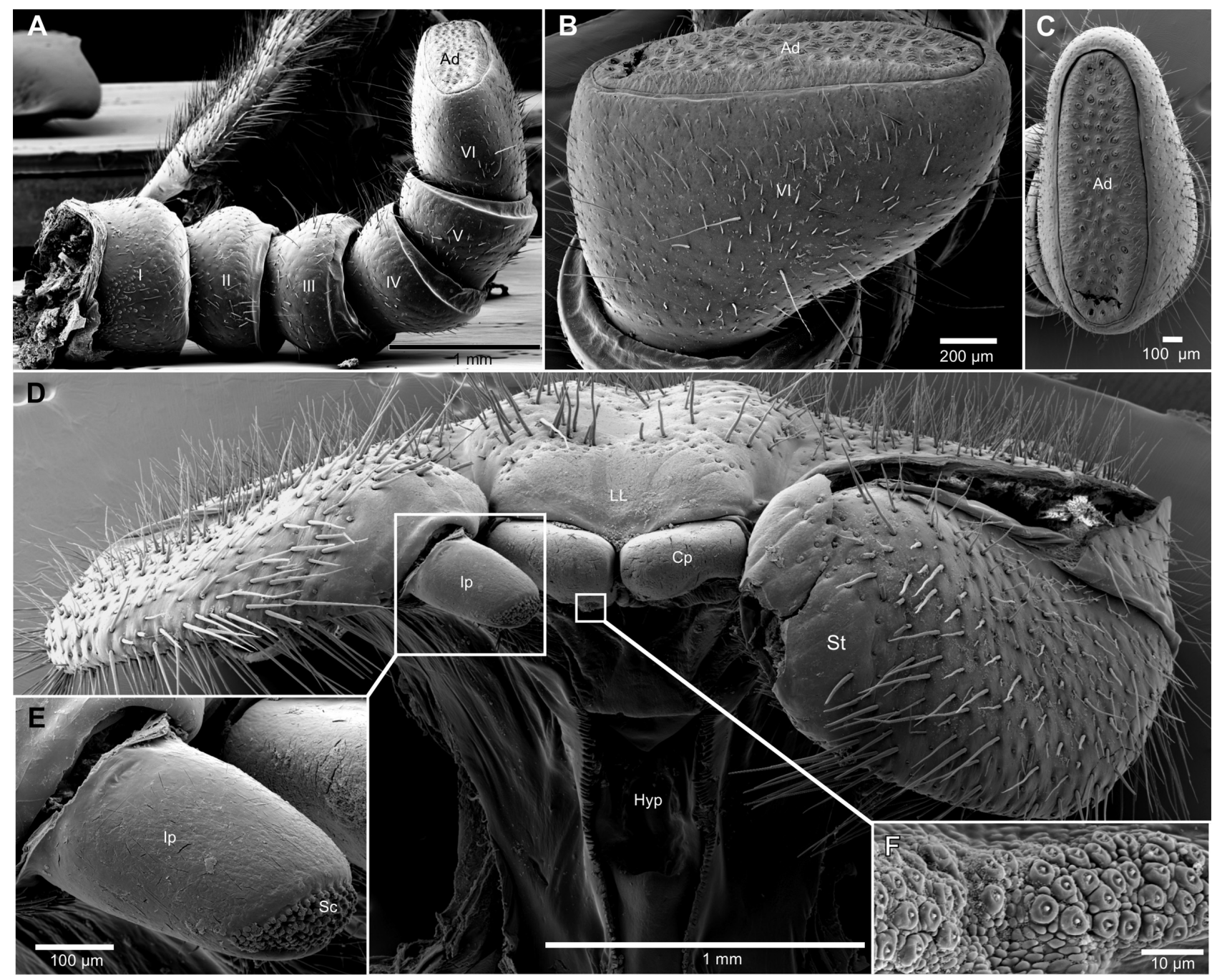

FIGURE 8. Zephronia chrysomallos Bhansali \& Wesener sp. nov., holotype $\precsim$ (ZFMK MYR8826), scanning electron micrographs. A. Left antennae, lateral view. B. Left sixth antennomere with antennal disc. C. Left antenna, disc. D. Gnathochilarium, apical view. E. Left lateral palpi. F. Left central pad, two types of sensory cones on central pad, detail. Abbreviations: $a c=$ apical cone; $a d=$ antennal disc; $\mathrm{Cp}=$ central pad; Hyp = hypopharynx; Ip = inner palpi; $L L=$ lamellae lingulales; $\mathrm{Sc}=$ sensory cone; $\mathrm{St}=$ stipites.

Epipharynx. With a large inner tooth.

Gnathochilarium (Figs 7D, 8D-F, 9A). Lamellae linguales with numerous long setae, more towards the margins. Stipes and mentum with numerous long setae in a regular pattern (Fig. 9A). Gnathochilarium palpi with sensory cones arranged in single field (Fig. 8E). 'Pillows' of central pads with two types of sensory cones (Fig. $8 \mathrm{~F})$.

Mandible (Fig. 9B). External tooth undivided, inner tooth with 3 lobes. Pectinate lamellae with 6 or 7 rows. Condylus at anterior margin with two distinct ridges.

Collum (Figs 7A, C). With few setae distributed towards the margins, more concentrated towards lateral ends.

Thoracic shield. Thoracic shield grooves wide and shallow (Figs 7A-C), without sclerotized ledges.

First stigmatic plate (Fig. 10A). Smaller than coxa, with rounded sub-triangular apex.

Tergites. Tergites densely covered in short, dense setae visible at higher magnification, with dull orange skinlike surface (Fig. 2B). Paratergite tips only weakly projecting backwards (Fig. 7B).

Pleurites. Pleurite 1 well-rounded, weakly projecting. Pleurite 2 well-rounded, not projecting (Fig. 7C).

Endotergum (Fig. 6B). With a regular flat margin. Outer area with two dense rows of marginal setae, reaching $4 / 5$ of outer area. Middle section with a single row of rounded cuticular impression, distance between impression 2-3 times their diameter. Inner area without setae or spines. 

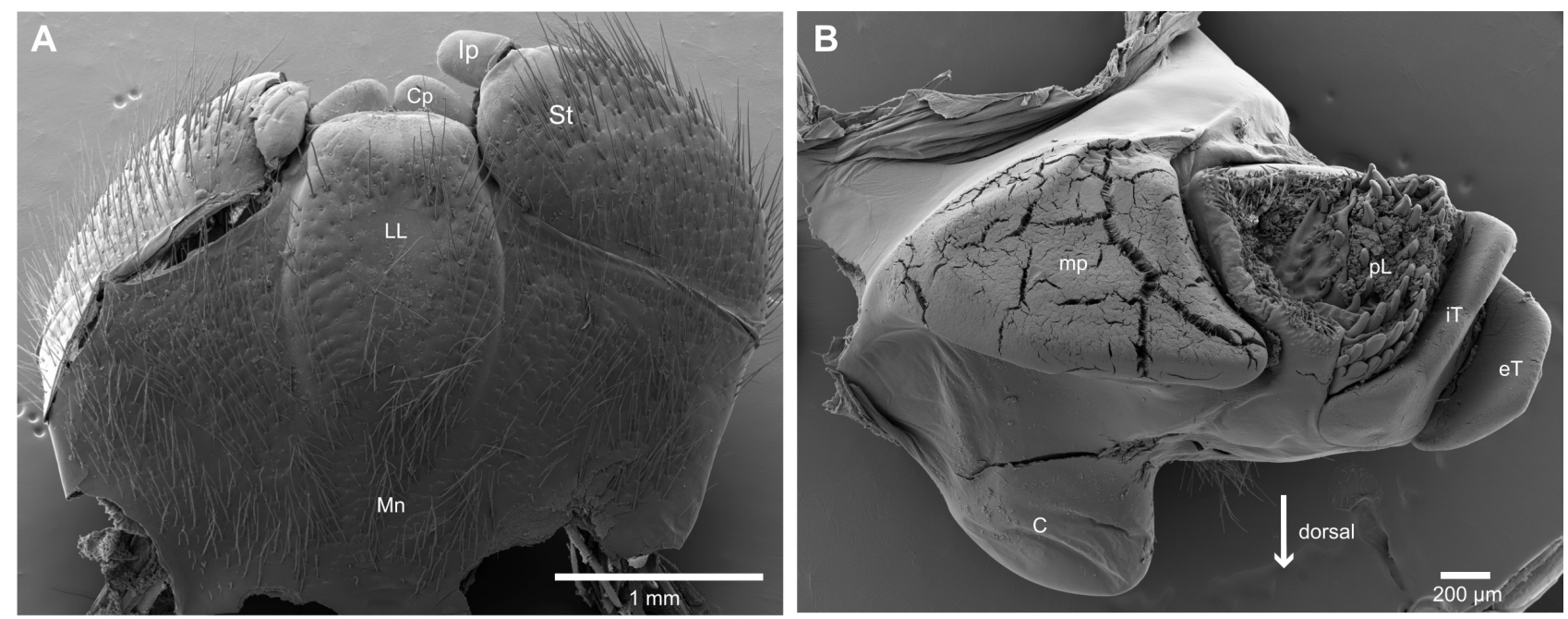

FIGURE 9. Zephronia chrysomallos Bhansali \& Wesener sp. nov., holotype $\widehat{\jmath}$ (ZFMK MYR8826), scanning electron micrographs. A. Gnathochilarium, ventral view. B. Right mandible, mesal view. Abbreviations: $\mathrm{C}=\mathrm{condyles} ; \mathrm{Cp}=\mathrm{cental}$ pad; eT = external tooth; $\mathrm{Ip}=$ inner palpi; $\mathrm{iT}=$ internal combined tooth; $\mathrm{LL}=$ lamellae linguales; $\mathrm{Mn}=$ mentum; $\mathrm{pL}=\mathrm{pectinate}$ lamellae; $\mathrm{St}=$ stipites.

Legs. Ventral spines on leg 1 2/2, at $24 / 4$, at 3 5/5. Leg 3 with single apical spine. Mid-body legs with 3 or 4 apical and 10-12 ventral spines (Fig. 10B). Inner margin of femur with 12-15 small triangular teeth, concentrated at apical half, but not excavated. Femur 1.5, tarsus 3.3 times longer than wide.

Anal shield. Well-rounded and like tergites covered with short dense setae visible at higher magnification (Fig. 2B). Ventral side with dark-colored medium-sized locking carina placed slightly closer to pleurite than margin (Fig. 7C).

Male sexual characters. Male gonopore consisting of large membranous opening located directly at mesal margin of coxa 2 (Fig. 10C). Coxae 2 without membranous processes.

Anterior telopods (Figs 10D-F). Syncoxite setaceous. Podomere 1 rectangular, as long as wide. Few setae, mainly at margins and in apical half. Podomere 2 in anterior view as wide as but slightly narrower as podomere 1. Process massive, visible in anterior view (Fig. 10E), relatively short and wide. Process protruding above basal half of podomere 3, triangular (Figs 10E, F). Podomere 3 cylindrical, 1.4 longer than wide, with one spine in the mesal membranous region, apically with 4 crenulated teeth (Fig. 10D). Podomere 4 clearly separated from podomere 3 , conical bearing a black spot at apex. Meso-posterior margin with two spines.

Posterior telopods (Fig. 11). Syncoxite inner horns (not drawn): apex well rounded, apically diverging. Podomere 1 rectangular, as wide as long, with short setae. Podomere 2 with long and narrow immovable finger, 5 times longer than wide. Immovable finger slightly wider posteriorly and apically very slightly curved towards movable finger. Immovable finger glabrous, remaining part of podomere 2 setose. Membranous lobe bearing 2 elongated processes, fused at base. Podomere 3 in posterior view glabrous, in anterior view basal half setose. With a row of 17 or 18 large crenulated square teeth on posterior side (Fig. 11B). Membranous ledge on podomere 3 with single spine. Podomere 4 on both sides glabrous, slightly curved towards immovable finger, membranous lobe with 2 spines. Immovable finger shorter than movable finger.

\section{Distribution}

Z. chrysomallos $\mathbf{s p . ~ n o v . ~ i s ~ c u r r e n t l y ~ o n l y ~ k n o w n ~ f r o m ~ t h e ~ t y p e ~ l o c a l i t y ~ n e a r ~ t h e ~ S a i ~ Y o k ~ N o i ~ W a t e r f a l l ~ ( F i g . ~ 2 A ) ~}$ and might be microendemic, as are other, closely related species in nearby forests.

\section{Zephronia erawani Bhansali \&Wesener, new species}

Figures 2A, 12, 13, 14.

Diagnosis. The position of the organ of Tömösváry at the brim and not in the antennal groove identifies this species as a member of the Zephronia senso-stricto group with which it also aligns weakly genetically. The sensory cones 
on the palpi of the gnathochilarium are arranged in a single field, not in separate clusters and the body is covered in a dense coat of golden setae like in several other Thai Zephronia. The greyish-brown color resembles those of $Z$. chrysomallos sp. nov. and Z. panhai. The male second leg mesal coxal margin is extended into a membranous process (Fig. 13B arrow), a character shared only with Z. golovatchi and Z. enghoffi. Z. erawani sp. nov. differs from both $Z$. golovatchi and $Z$. enghoffi in the shorter marginal bristles of the endotergum which end well before the margin, while the bristles are projecting above the two in both other species.

Z. erawani sp. nov. differs genetically in the COI barcoding fragment from Z. panhai by a p-distance of $11.6 \%$, from Z. chrysomallos $\mathbf{s p . ~ n o v . ~ b y ~ a ~ p - d i s t a n c e ~ o f ~} 11.9 \%$ and from Z. lannaensis by $12.6-13.3 \%$ (Sup. file 1).

Derivatio nominis. Named after the type locality, the Erawan waterfalls. Erawan is a mythological elephant, similar to the Hindi Airavata. Noun in apposition.

Material examined (total: $1 \precsim$ )

Holotype:

THAILAND: 1 ภ, NHMD K56-9, Kanchanaburi Province, Si Sawat District, 50 km W of Kanchanaburi, Erawan Waterfall, [probably: 14²1'31.32"N, 99 8'26.23"E, 377 m], 6.VI.1990, leg. A. R. Rasmussen \& B. Helwigh.

Description (based on holotype)

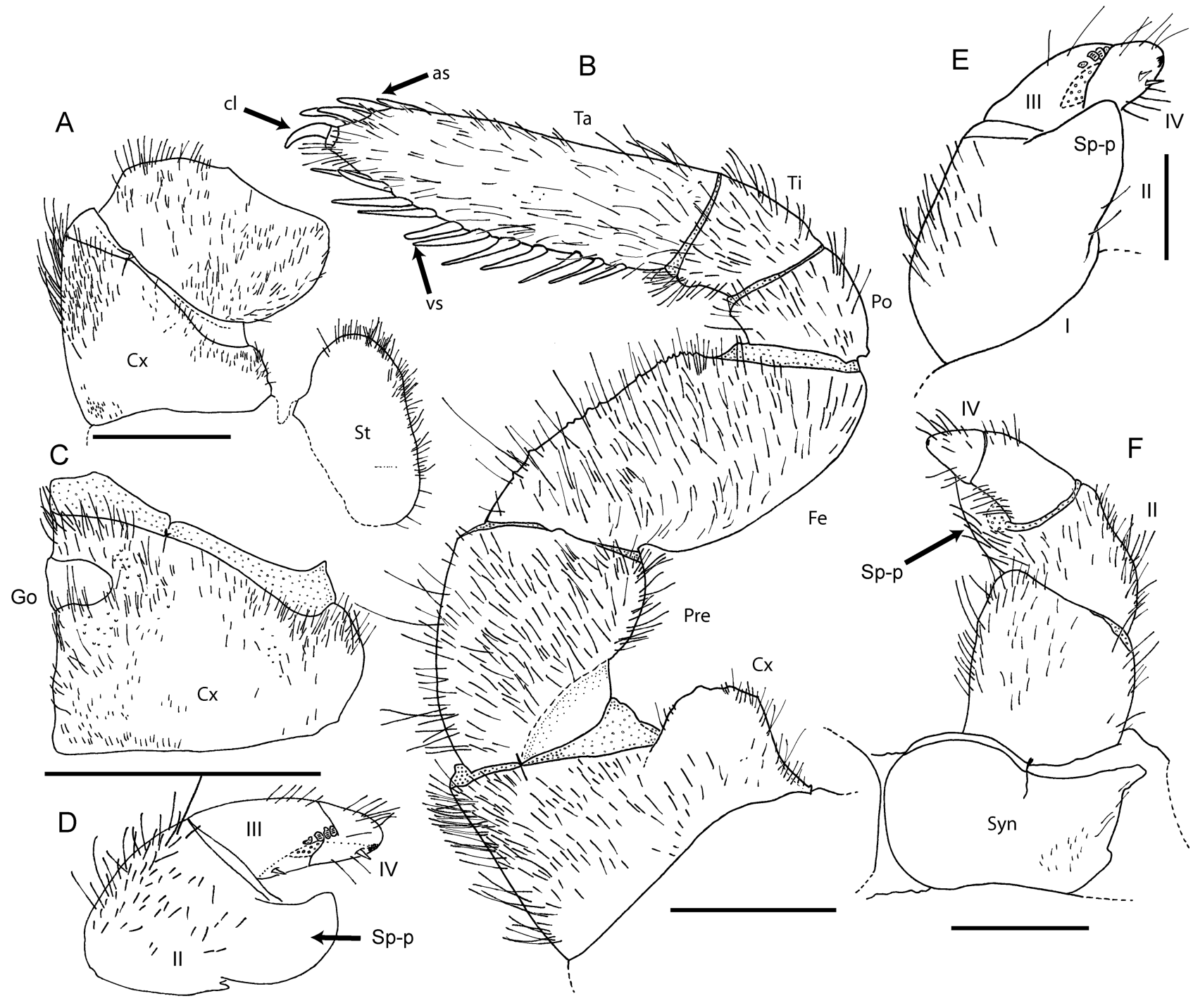

FIGURE 10. Zephronia chrysomallos Bhansali \& Wesener sp. nov., holotype $ð$ (ZFMK MYR8826), drawings, A. First left coxa with stigmatic plate, posterior view. B. Left leg 9, posterior view. C. Second left coxa with gonopore, posterior view. D. Right anterior telopod, lateral view. E. Right anterior telopod, posterior view. F. Right anterior telopod, anterior view. Abbreviations: as = apical spine; $\mathrm{cl}=$ claw; $\mathrm{Cx}=$ coxa; $\mathrm{Fe}=$ femur; $\mathrm{Go}=$ gonopore; $\mathrm{Po}=$ postfemur; Pre $=$ prefemur; $\mathrm{Sp}-\mathrm{p}$ $=$ second podomere process; $\mathrm{St}=$ stigmatic plate; $\mathrm{Syn}=$ syncoxite $; \mathrm{Ta}=$ tarsus; $\mathrm{Ti}=$ tibia; vs $=$ ventral spines. Scale bars $=1$ $\mathrm{mm}$. 


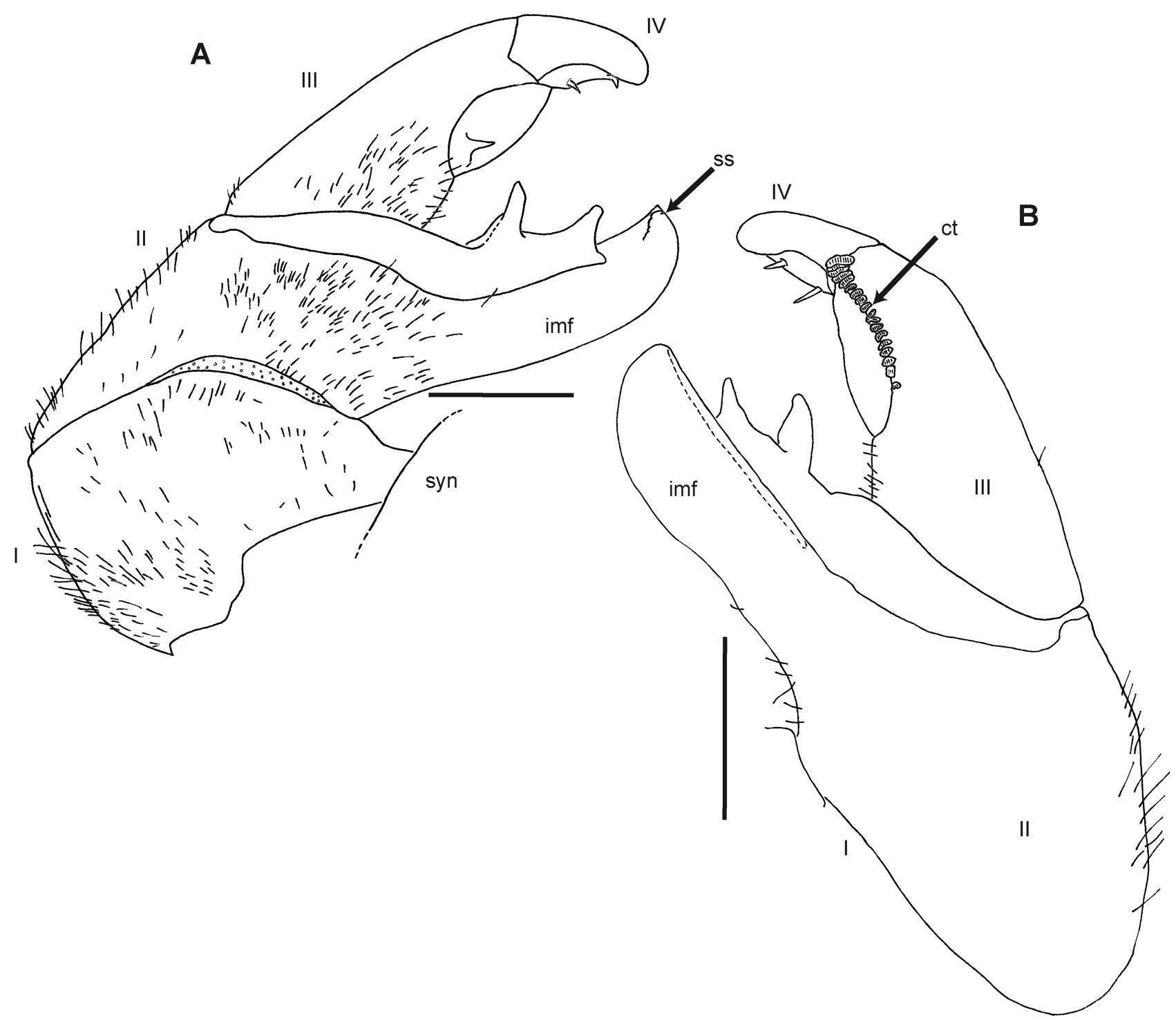

FIGURE 11. Zephronia chrysomallos Bhansali \& Wesener sp. nov., holotype $\widehat{\jmath}$ (NHMD MYR8826), drawings, A. Left posterior telopod, anterior view. B. Left posterior telopod, posterior view. Abbreviations: $\mathrm{ct}=$ crenulated teeth; imf = immovable finger; ss $=$ sclerotized spot. Scale bars $=1 \mathrm{~mm}$.

Size. Length: $31.4 \mathrm{~mm}$. Width of thoracic shield $14.8 \mathrm{~mm}$, of widest segment (6) $16.5 \mathrm{~mm}$. Height of thoracic shield $9.3 \mathrm{~mm}$, of highest segment (6) $9.8 \mathrm{~mm}$.

Colour. Faded after 30 years in $75 \%$ ethanol. Collum medium brown, head and legs with traces of green. Antenna green. Tergites and anal shield pale greyish-brown, darker brown towards posterior margin. Thoracic shield-like tergite with darker groove and margins. Anal shield colour like tergite.

Head. Number of ommatidia 95. Tömösváry organ placed on the rim of antennal groove. Antennae short, not reaching to center of head (Fig. 12A-D). Antennomere lengths: $1>2=3=4=5<<6$. Antennomer 6 laterally flattened, apically widened, axe-shaped, carrying 91/96 apical cones.

Epipharynx. Not dissected.

Gnathochilarium (Fig. 12D). Gnathochilarium palpi with the sensory cones arranged in single field.

Mandible. Not dissected.

Collum. Numerous setae, distributed towards margins, few setae in central region.

Thoracic shield. Thoracic shield grooves shallow and wide with 2 or 3 weak ledges (Fig. 12A, B).

First stigmatic plate. Smaller than coxa, rounded apex.

Tergites. Tergites covered in short, dense setae visible at higher magnification, with dull orange skin-like surface. Paratergite tips weakly projecting backwards (Fig. 12A, B). 
Pleurites (Fig. 12C). Pleurite 1 projecting, tip well-rounded. Pleurite 2 well-rounded, weakly projecting.

Endotergum. With a regular flat margin. Outer zone with three dense rows of irregular marginal setae, not extending beyond posterior margin, but reaching $4 / 5$ of the outer area. Middle section with cuticular impressions. Inner area without setae.

Legs. Ventral spines on leg 1 2/2, at $24 / 4$, at 3 7/7. Leg 3 with single apical spine. Mid-body legs with 2 or 3 apical and 8-10 ventral spines (Fig. 13A). Inner margin of femur with 14 small triangular teeth, concentrated at apical half, but not excavated. Femur 1.7, tarsus 3.6 times longer than wide.

Anal shield. Bell-shaped and like tergites covered with short dense setae visible at higher magnification. Underside with single black locking carina of medium length, located close to pleurite (Fig. 12C).
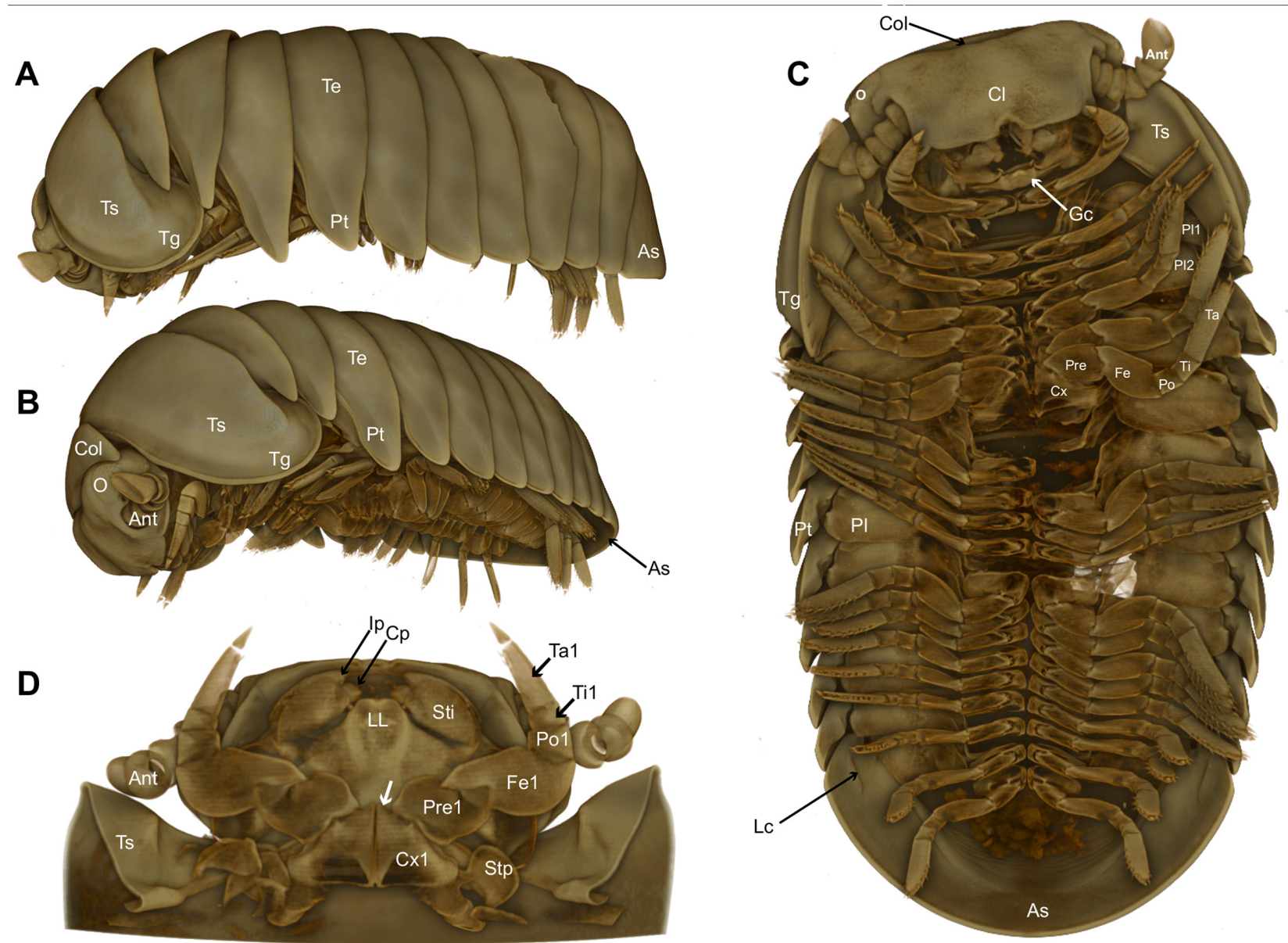

FIGURE 12. Zephronia erawani Bhansali \& Wesener sp. nov., holotype $\widehat{\jmath}$ (NHMD K56-9), volume rendering based on microcomputed tomography. A. Habitus, lateral view. B. Habitus, ventro-lateral view. C. Habitus, ventral view. D. Habitus, anterior view. E. Body-ring architecture, cross section trough midbody-ring. Abbreviations: $\mathrm{Ant}=\mathrm{Antennae} ; \mathrm{As}=$ anal shield; $\mathrm{Cl}=$ clypeus; $\mathrm{Col}=$ collum; $\mathrm{Cp}=$ central pad; $\mathrm{Cx}=$ coxa $\mathrm{Fe}=$ femur $\mathrm{Gc}=$ gnathochilarium; $\mathrm{Go}=$ gonopore; $\mathrm{Ip}=$ inner palpi; $\mathrm{Lc}=$ locking carina; $\mathrm{o}=$ ommatidia; $\mathrm{Pl}=$ pleurite; $\mathrm{Pl1}=$ pleurite $1 ; \mathrm{Pl}=$ pleurite $2 ; \mathrm{Po}=$ postfemur; $\mathrm{Pre}=$ prefemur; $\mathrm{Pt}=$ paratergite; $\mathrm{Stp}=$ stigmatic plate; $\mathrm{St}=$ stipites; $\mathrm{Ta}=$ tarsus; $\mathrm{Te}=$ tergite; $\mathrm{Tg}=$ thoracic shield groove; $\mathrm{Ti}=$ tibia; $\mathrm{Ts}=$ thoracic shield. Not to scale.

Male gonopore. Located directly on mesal margin of coxa 2, covered posteriorly by a single semicircular sclerotized plate. Membrane rising mesally into a projection (Fig. 13B).

Anterior telopods (Fig. 13C-E). Syncoxite with few setae. Podomere 1 rectangular, as long as wide. Numerous setae, mainly at median margins. Podomere 2 slightly narrower than podomere 1. Process massive, well-rounded, apically slightly tapering, relatively short and wide (Fig. 13D, E). Process visible protruding and exceeding podomere 3 in anterior view (Fig. 13D). Podomere 3 cylindrical, with a black spot at the anterior margin visible in posterior view. Podomere 4 partially fused to podomere 3, suture can be seen in anterior view (Fig. 13C), while it is completely fused in posterior, lateral and mesal views. Podomere 4 small, narrowing at the apex. Meso-anterior margin with one spine and a black spot at apex visible in posterior and lateral view. 

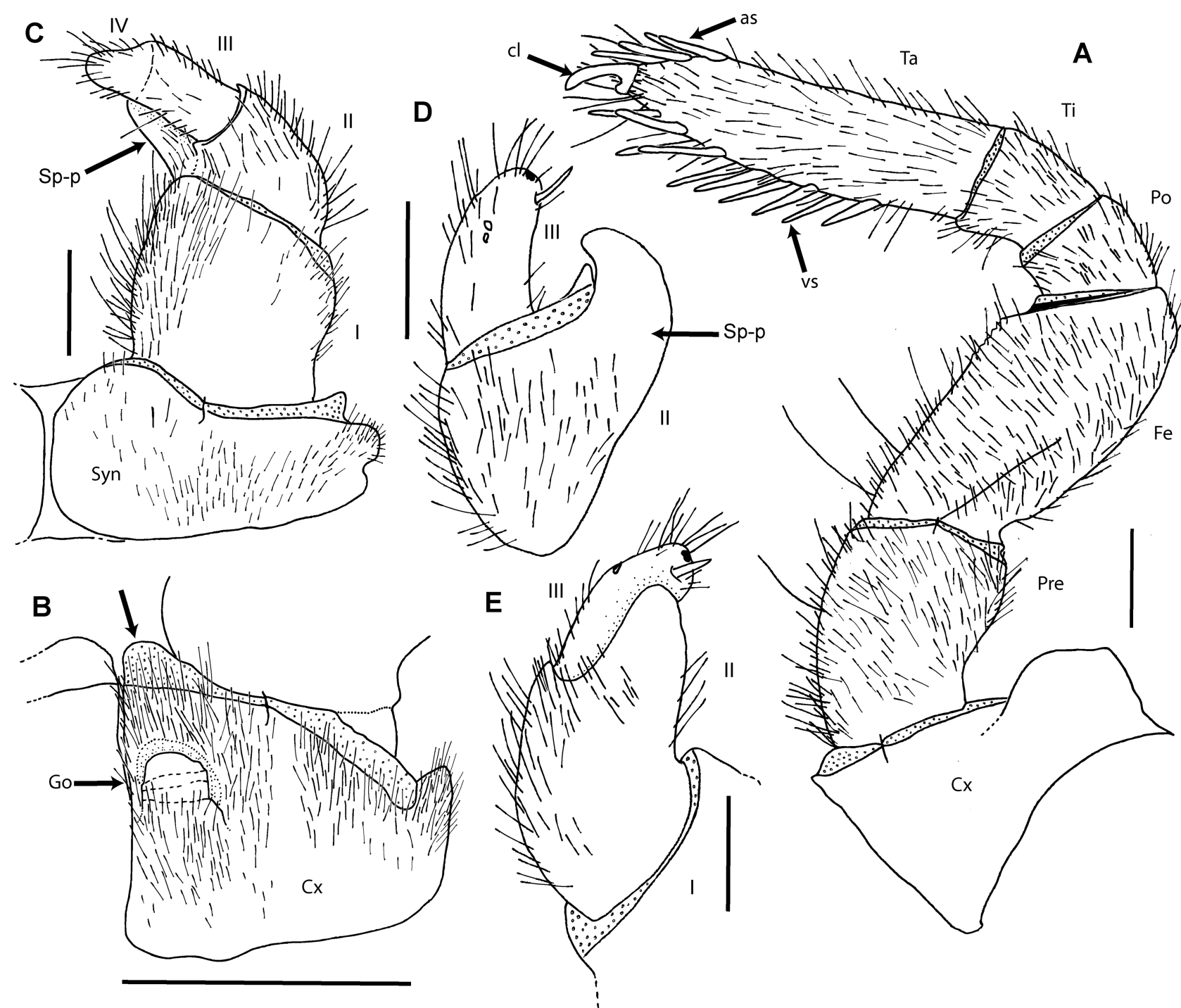

FIGURE 13. Zephronia erawani Bhansali \& Wesener sp. nov., holotype $ð$ (ZMUC K56-9), drawings, A. Left leg 9, posterior view B. Second left coxa with gonopore, posterior view. C. Right anterior telopod, anterior view. D. Right anterior telopod, lateral view. E. Right anterior telopod, posterior view. Abbreviations: as = apical spine; $\mathrm{cl}=\mathrm{claw} ; \mathrm{Cx}=\mathrm{coxa} ; \mathrm{Fe}=\mathrm{femur}$; $\mathrm{Go}=$ gonopore; $\mathrm{Po}=$ postfemur; Pre = prefemur; $\mathrm{Sp}-\mathrm{p}=$ second podomere process; $\mathrm{St}=$ stigmatic plate; $\mathrm{Syn}=$ syncoxite $; \mathrm{Ta}=$ tarsus; $\mathrm{Ti}=$ tibia; vs $=$ ventral spines. Scale bars $=1 \mathrm{~mm}$.

Posterior telopods (Fig. 14). Syncoxite inner horns (not drawn): apex well rounded, apically diverging. Podomere 1 with short setae distributed in median and lateral margin, median margin glabrous. Podomere 2 with long and wide immovable finger, 2.5 times longer than wide. Podomere 2 with numerous setae visible in anterior view, almost entirely glabrous in posterior view. Immovable finger slightly narrow anteriorly and straight. Apical process with sclerotized round spots in anterior view (Fig. 14A, arrow). Membrane toward podomere 3 with a two-tipped membranous lobe. Podomere 3 setose in anterior view, with more setae concentrated medially. With row of 15 large, crenulated teeth on posterior side (Fig. 14B, arrow). Large membranous ledge on podomere 3 with single spine present basal region. Podomere 4 glabrous on both sides, slightly curved towards immovable finger. Membranous lobe with 2 long spines. Immovable finger shorter than movable finger.

\section{Distribution}

Z. erawani sp. nov. is currently only known from the type locality (Fig. 2A) and might be microendemic, as are other, closely related species in nearby forests. 


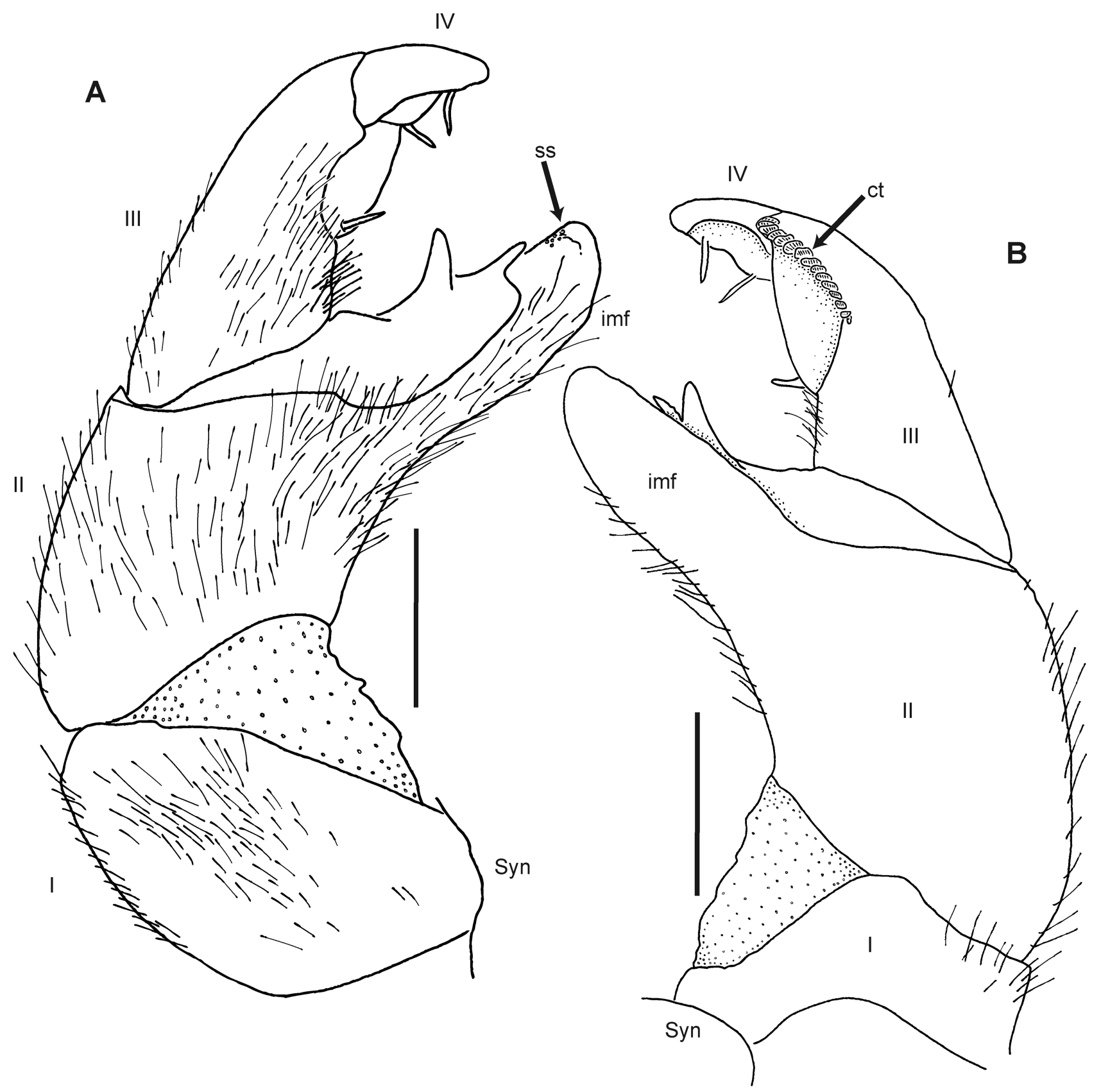

FIGURE 14. Zephronia erawani Bhansali \& Wesener sp. nov., holotype $\widehat{\jmath}$ (NHMD K56-9), drawings, A. Left posterior telopod, anterior view. B. Left posterior telopod, posterior view. Abbreviations: $\mathrm{ct}=$ crenulated teeth; imf $=$ immovable finger; ss $=$ sclerotized spot. Scale bars $=1 \mathrm{~mm}$.

\section{New locality data for Thai Zephroniidae}

\section{Zephronia phrain Likhitrakarn \& Golovatch in Likhitrakarn et al. 2021}

New locality data: $1 \hat{\delta}$, SMF, Chiang Mai Province, Chiang Dao District $20 \mathrm{~km}$ NNE of Chiang Dao, Tham Houay Luk, 19³2'18"N, 99²'44"E, 623 m, outside cave, by hand, leg. 26.VI.2014, P. Jäger \& E. Grall; 1 ô, SMF, Chiang Mai Province, Chiang Dao District, Doi Chiang Dao, Ma Lee's Resort, 19²4'12"N, 98 55'34"E, 470 m, garden, by hand, by day and night, leg. 24-30.VI.2014, P. Jäger \& E. Grall; 1 ô, 1 q, SMF, Chiang Mai Province, Chai Prakan District, near Si Dong Yen, ThamNgam [=pretty cave], 19³9'19.46"N, 996'11.10"E, $660 \mathrm{~m}$, inside cave and in front of cave, by day, by hand, leg. 29.VI.2014, P. Jäger \& E. Grall; 1 §ิ, ZFMK MYR4907, Chiang Mai, Chiang Dao,

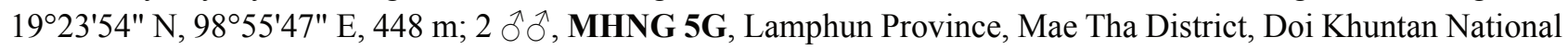




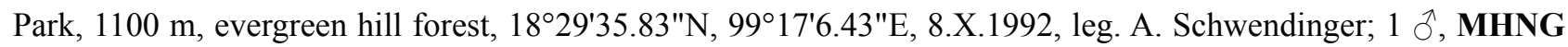
5I, Province Chiang Mai, Chiang Dao District, Doi Chiang Dao, 400 m, 7.VII.1987, leg. P. Schwendinger; 1 đ, ZFMK MYR3499, Chiang Mai Province, District Chiang Dao, Padeng Lodge, 03.VII.2014, leg. S. Huber; 1 đ, ZFMK MYR3500, Chiang Mai Province and District, Doi Suthep, behind tourist market, $18^{\circ} 48^{\prime} 03^{\prime \prime} \mathrm{N}, 98^{\circ} 55^{\prime} 05^{\prime \prime}$ E, 2040 m, leg. 29.VI.2014, S. Huber; 1 đ, ZFMK MYR4907, Chiang Mai Province, Chiang Dao, 19²3'54"N, 985' $47^{\prime \prime}$ E, 448 m, 14-16.VIII.2015.

Remarks. This species, as already mentioned previously (Srisonchai et al. 2021), is more widespread than previously thought (Fig. 2A). We observed a lot of intraspecific variation in the genetic barcode (Sup. file 1) as well as in the telopods of $Z$. phrain, so there might be cryptic species under this name.

\section{Zephronia lannaensis Likhitrakarn \& Golovatch, 2021 in Likhitrakarn et al. 2021}

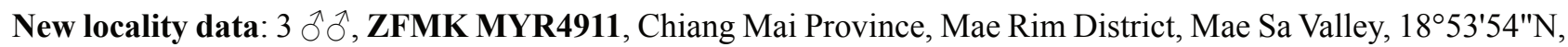
98 51'16"E, 650 m, 31.VIII-03.IX.2015; 2 ô के, NHMD K57B, Chiang Mai Province and District, Doi Suthep, Mae Sa Waterfall, 29.V.1991, leg. C.C. Kinze; 1 ðै, MHNG 3B; Chiang Mai Province \& District, Doi Suthep, 800 m, evergreen gallery forest, 12.V.1986, leg. P. Schwendinger; 1 q, ZFMK MYR3498, Chiang Mai Province and

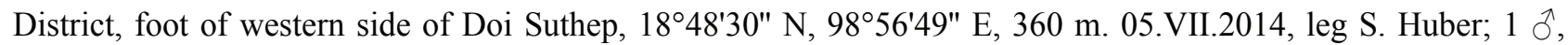
ZFMK MYR3501, Chiang Mai Province, Mae Rim District, Traidhos School Campus, 1857'57" N, 98 $55^{\prime} 05^{\prime \prime}$

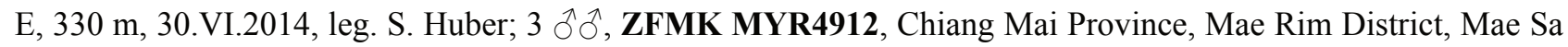
Valley, 1853'54" N, 9851'16" E, 650 m, 31.VIII-03.IX.2015.

Remarks. The localities mentioned above lie close to the type locality (Fig. 2A).

\section{Zephronia panhai Srisonchai, Sutcharit \& Likhitrakarn, 2021}

New locality data: 1 , ZFMK MYR8116, Ratchaburi Province, Ratchaburi and Photharam District, 18-20 km

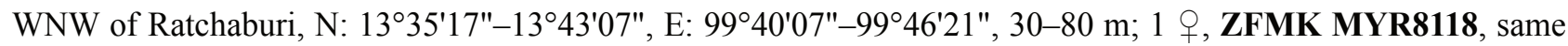

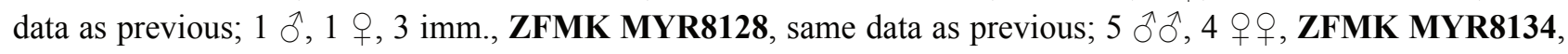
same data as previous; $4 \hat{\partial} \hat{\partial}, 1$, MHNG 3A, Ratchaburi Province, Chombueng District, Tham Khao Bin Forest Park, $70 \mathrm{~m}$, secondary forest on limestone, $13^{\circ} 35^{\prime} 12^{\prime \prime} \mathrm{N}, 9^{\circ} 40^{\prime} 01^{\prime} \mathrm{E}, 27 / 28 . V I .2011$, leg. P. Schwendinger, sample TH-11/01.

Remarks. The localities mentioned above are close to the type locality (Fig. 2A).

\section{Zephronia golovatchi Srisonchai, Sutcharit \& Likhitrakarn, 2021}

New locality data: 1 , ZFMK MYR6262, Nakhon Ratchasima Province, Pak Ching District, near Highway 3052 ,

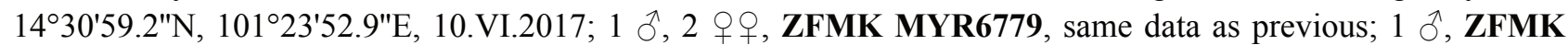
MYR7236, same data as previous; 2 우, NHMD K53, Nakhon Nayok Province, Khao Yai National Park, 700 m, leg. 29.IX-6.X.1984, leg. Karsholt, Lomholdt \& Nielsen.

Remarks. Both localities lie close to the type locality (Fig. 2A). However, specimens from both localities differ significantly genetically and might represent two different species.

\section{Updated key to confirmed species of Zephronia in Thailand}

1: Tarsi of leg pair 4-21 with single apical spine, third leg pair without apical spine. Male antennae, antennomere 6 swollen, not axe-shaped. . ........................... . viridisoma Rosenmejer \& Wesener in Rosenmejer et al. 2021 Tarsi of leg pair 4-21 with 3 apical spines, third leg pair with apical spine. Male antennae, antennomere 6 axe-shaped. . . . 2

2: Conspicuous colour pattern with a vivid green, glabrous or dull, not golden setae. Palpi of gnathochilarium, sensilla in

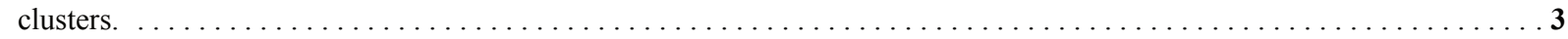
Brown, grey, or brown-greenish color pattern with dense coat of 'golden' setae. Palpi of gnathochilarium, sensilla in single

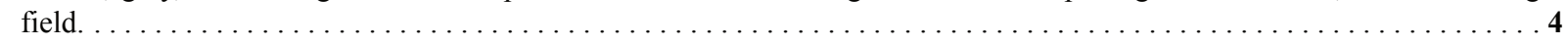


3: $\quad$ Small bodied, around $20 \mathrm{~mm}$. Unique color pattern, green-whitish with red on the anal shield. Tergites setose, dull. Anterior telopod, podomere 3 with up to 7 crenulated teeth. Antennae, antennomere 6 with 50-60 cones. . . . Z. siamensis Hirst, 1907 Large, around $40 \mathrm{~mm}$. Unique color pattern, with a vivid green-lightbrownish stripes. Tergite glabrous, shiny. Anterior telopod variable, without or only very few sclerotized teeth. Antennae, antennomere 6 with 70-90 cones.

Z. phrain Likhitrakarn \& Golovatch in Likhitrakarn et al. 2021

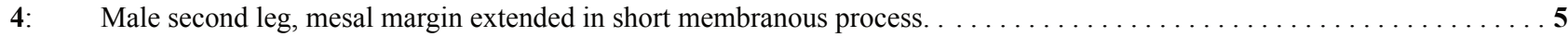

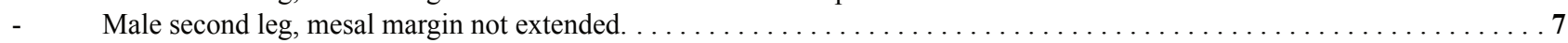

5: $\quad$ Endotergum, two rows of marginal bristles which project beyond tergite margin $\ldots \ldots \ldots \ldots \ldots \ldots \ldots \ldots \ldots \ldots \ldots$ Endotergum, two rows of marginal bristles which end clearly before the tergite margin. . ........... Z. erawani sp. nov.

6: Female vulval operculum margin straight and wide. Antennae, antennomere 6 with $90-100$ cones. Male anal shield bell-shaped. Female vulval operculum narrow in posterior view. Antennae, antennomere 6 with around 75 cones. Male anal shield

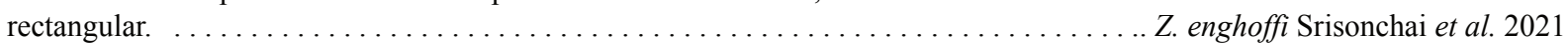

7: $\quad$ Brown. Inner area of endotergum without setae. . . . . . . Z. lannaensis Likhitrakarn \& Golovatch in Likhitrakarn et al. 2021

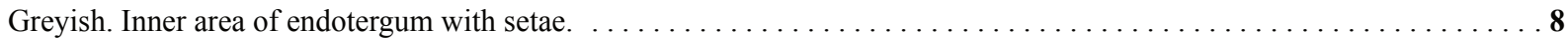
Small, 20-22 mm long. Legs with 7-9 ventral spines. Male antennae, antennomere 6 with ca. 50 cones. Pleurite 1 extended into long, sharp tip. Endotergum with two rows of marginal bristles. . . . . . . . . . . . . . . panhai Srisonchai et al. 2021 Medium, $40 \mathrm{~mm}$ long. Legs with 10-12 ventral spines. Male antennae, antennomere 6 with 78-88 apical cones. Pleurite 1 weakly extended, well-rounded. Endotergum with three rows of marginal bristles. . . . . . . Z. chrysomallos sp. nov.

\section{Discussion}

Biogeography and genetic distance of newly described Sphaerobelum. Sphaerobelum meridionalis sp. nov. and S. aesculus differ from all previously described Sphaerobelum morphologically, geographically, and genetically. The immovable finger with a swollen apex is an important character for the characterization of the genus Sphaerobelum (Enghoff et al. 2015; Wesener 2019; Zhao et al. 2020). Unlike other Sphaerobelum species which possess a swollen apex of the immovable finger (Wongthamwanich et al. 2012; Wesener 2019), S. meridionalis sp. nov. and S. aesculus have a weak swelling in the center of the posterior side of the immovable finger, which is in other characters usual for Zephroniidae millipedes (Wesener 2016). Being quite distant geographically and genetically (p-distance of $>17 \%$ ) from other Sphaerobelum species, there is a possibility that both S. meridionalis sp. nov. and S. aesculus need to be placed in a genus different from Sphaerobelum. Malaysian giant pill-millipedes need to be reviewed in order to see if the two recently described Sphaerobelum might belong to a Malaysian genus (Jeekel 2000; Mauriès 2001). Especially a revision of Malaysian species, not done since the 1950s, is urgently needed.

Intra- and interspecific genetic distances. DNA barcoding is becoming an increasingly important tool for efficiently delimiting organisms at species-level using the mitochondrial COI gene (Hebert et al. 2003). Genetic barcoding helps to correctly determine samples only represented by females or juveniles at the genus- and specieslevel, as well as identify cryptic species (Wesener \& Conrad 2016), or color variants of widespread species (Reip $\&$ Wesener 2018). In our new dataset, the observed interspecific distances of the three new Thai Zephroniidae species in comparison with related species are similar (minimum 10.8\%) to those observed in giant pill-millipedes from Madagascar, where the species of Sphaeromimus de Saussure \& Zehntner, 1902 show interspecific distances of 8.3-20.8\% (Wesener et al. 2014; Moritz \& Wesener 2017), while the interspecific distances in the less wellsampled genus Zoosphaerium Pocock, 1895 are 9.1-20\% (Sagorny \& Wesener 2017; Wesener \& Anilkumar 2020; Wesener \& Sagorny 2021). One reason behind the large interspecific distances between our three new species from southern Thailand might be that their closest relatives have not been discovered or sampled yet. Z. panhai and $Z$. lannaensis show intraspecific distances as seen between most populations of millipedes. On the other hand, our results show surprisingly high intraspecific distances in between populations of Z. phrain and Z. golovatchi. Future morphological studies should test whether the high intraspecific distances observed in these two species are in fact due to intraspecific variation, or whether these populations represent additional undescribed Thai Zephronia species.

\section{Acknowledgements}

This work is part of a lab class for the International Master's Study program in "Organisms, Evolution and Paleontology" at the University of Bonn. Many thanks to the curators Peter Schwendinger (MHNG), Peter Jäger 
(SMF) and Henrik Enghoff (NHMD) for loaning out their substantial giant pill-millipede collections. Claudia Etzbauer (ZFMK) is thanked for her assistance in the molecular lab. We thank Thorsten Klug (ZFMK) for help with the scanning electron microscope, and for general assistance throughout the project. Benjamin Wipfler is thanked for providing an introduction to the CT scanner. We are also grateful to Leif Moritz for helping with the CT scanning, the uploading of the cybertype data, as well as help at the SEM. Special thanks go to Pooja A. Anilkumar for making the map and providing assistance in digitally editing the figure plates. Natdanai Likhitrakarn, Ruttapon Srisonchai and Peter Schwendinger provided comments on a previous draft which greatly improved this manuscript. Ruttapon Srisonchai checked the collections at CUMZ for additional specimens of $Z$. chrysomallos for which we are very grateful. The two reviewers H. Enghoff and J. Means as well as the editor D. Antić provided numerous corrections and comments which greatly improved the here presented work.

\section{References}

Alagesan, P. (2016) Millipedes: Diversity, Distribution and Ecology. In: Chakravarthy, A.K. \& Sridhara, S. (Eds.), Arthropod Diversity and Conservation in the Tropics and Sub-tropics. Springer, Singapore, pp. 119-137. https://doi.org/10.1007/978-981-10-1518-2_7

Altschul, S.F., Madden, T.L., Schäffer, A.A., Zhang, J., Zhang, Z., Miller, W. \& Lipman, D.J. (1997) Gapped BLAST and PSIBLAST: a new generation of protein database search programs. Nucleic Acids Research, 25, 3389-3402. https://doi.org/10.1093/nar/25.17.3389

Astrin, J.J. \& Stüben, P.E. (2008) Phylogeny in cryptic weevils: molecules, morphology and new genera of western Palaearctic Cryptorhynchinae (Coleoptera: Curculionidae). Invertebrate Systematics, 22, 503. https://doi.org/10.1071/IS07057

Brewer, M.S., Sierwald, P. \& Bond, J.E. (2012) Millipede Taxonomy after 250 Years: Classification and Taxonomic Practices in a Mega-Diverse yet Understudied Arthropod Group. PLoS ONE, 7, e37240. https://doi.org/10.1371/journal.pone.0037240

Clements, R., Sodhi, N.S., Schilthuizen, M. \& Ng, P.K.L. (2006) Limestone Karsts of Southeast Asia: Imperiled Arks of Biodiversity. BioScience, 56, 733. https://doi.org/10.1641/0006-3568(2006)56[733:LKOSAI]2.0.CO;2

Enghoff, H. (2005) The millipedes of Thailand (Diplopoda). Steenstrupia, 29 (1), 87-103.

Enghoff, H., Golovatch, S., Short, M., Stoev, P. \& Wesener, T. (2015) Diplopoda. In: Minelli, A. (Ed.), Treatise on zoologyanatomy, taxonomy, biology. The Myriapoda, 2 (16), pp. 363-453.

Felsenstein, J. (1985) Confidence Limits on Phylogenies: An Approach Using the Bootstrap. Evolution, 39, 783-791 https://doi.org/10.2307/2408678

Golovatch, S.I. \& Kime, R.D. (2009) Millipede (Diplopoda) distributions: A review. Soil organisms, 81 (3), $565-597$.

Gray, G. (1832) The Myriapods (Myriapoda-Mitosata). In: Griffith, E. \& Pidgeon, E. (Eds.), The Class Insecta arranged by the Baron Cuvier, London, 2, pp. 1-796.

Hall, T. (1999) BioEdit: a user-friendly biological sequence alignment editor and analysis program for Windows 95/98/NT. Nucleic Acids Symposium Series, 41, 95-98.

Hebert, P.D.N., Cywinska, A., Ball, S.L. \& deWaard, J.R. (2003) Biological identifications through DNA barcodes. Proceedings of the Royal Society of London, Series B: Biological Sciences, 270, 313-321. https://doi.org/10.1098/rspb.2002.2218

Hirst, A.S. (1907) On four new pill-millipedes from the Malay Peninsula and Siam. The Annals and Magazine of Natural History, Series 7, 20 (117), 215-219. https://doi.org/10.1080/00222930709487327

Hoffman, R.L. (1980) Classification of the Diplopoda. Muséum d'Histoire Naturelle Genève, Genève, 237 pp.

Jeekel, C.A.W. ([1970] 1971) Nomenclator generum et familiarum Diplopodorum: A list of the genus and family-group names in the Class Diplopoda from the 10th edition of Linnaeus, 1758, to the end of 1957. Monografieen van de Nederlandse Entomologische Vereniging, 5, i-xii + 1-412.

Jeekel, C.A.W. (2000) A new genus of Sphaeropoeidae from Malaysia (Diplopoda, Sphaerotheriida). Myriapod Memoranda, 2, 68-70.

Likhitrakarn, N., Golovatch, S.I., Srisonchai, R. \& Sutcharit, C. (2021) Two New Species of the Giant Pill-Millipede Genus Zephronia Gray, 1832 from Thailand (Diplopoda: Sphaerotheriida: Zephroniidae). Tropical Natural History, 21, 12-26.

Limaye, A. (2012) Drishti: a volume exploration and presentation tool. In: Developments in X-Ray Tomography VIII. Proceedings of SPIE, 8506, pp. 191-199. https://doi.org/10.1117/12.935640

Mauriès, J.P. (2001) Sur I'identité de Zephronia hainani Gressitt, 1941, à propos de la description d'un nouveau Prionobelum (Diplopoda, Sphaerotheriida, Sphaeropoeidae) de Haïnan, Chine. Zoosystema, 23 (1), 131-142.

Moritz, L. \& Wesener, T. (2017) Integrative description of two new species of Malagasy chirping giant pill-millipedes, genus 
Sphaeromimus (Diplopoda: Sphaerotheriida: Arthrosphaeridae). European Journal of Taxonomy, 381, 1-25. https://doi.org/10.5852/ejt.2017.381

Pocock, R.I. (1895) Description of new genera of Zephronidae, with brief preliminary diagnose of some new species. Annals and Magazine of Natural History, Zoology, Botany and Geology Series, 6, 16, 409-415. https://doi.org/10.1080/00222939508680293

QGIS.org (2021) QGIS Geographic Information System. QGIS Association. Avaialble from: https://qgis.org/en/site/ (accessed 20 February 2022)

Reip, H.S. \& Wesener, T. (2018) Intraspecific variation and phylogeography of the millipede model organism, the Black Pill Millipede Glomeris marginata (Villers, 1789) (Diplopoda, Glomerida, Glomeridae). ZooKeys, 741, 93-131. https://doi.org/10.3897/zookeys.741.21917

Rosenmejer, T., Enghoff, H., Moritz, L. \& Wesener, T. (2021) Integrative description of new giant pill-millipedes from southern Thailand (Diplopoda, Sphaerotheriida, Zephroniidae). European Journal of Taxonomy, 762, 208-232. https://doi.org/10.5852/ejt.2021.762.1457

Sagorny, C. \& Wesener, T. (2017) Two new giant pill-millipede species of the genus Zoosphaerium endemic to the Bemanevika area in northern Madagascar (Diplopoda, Sphaerotheriida, Arthrosphaeridae). Zootaxa, 4263 (2), 273-294. https://doi.org/10.11646/zootaxa.4263.2.4

Saussure, H. de \& Zehntner, L. (1902) Myriapodes de Madagascar, in Grandidier A., Histoire physique, naturelle et politique de Madagascar, 27 (53), i-viii + 1-356.

Schindelin, J., Arganda-Carreras, I., Frise, E., Kaynig, V., Longair, M., Pietzsch, T., Preibisch, S., Rueden, C., Saalfeld, S., Schmid, B., Tinevez, J.-Y., White, D.J., Hartenstein, V., Eliceiri, K., Tomancak, P. \& Cardona, A. (2012) Fiji: an opensource platform for biological-image analysis. Nature Methods, 9, 676-682. https://doi.org/10.1038/nmeth.2019

Semenyuk, I., Golovatch, S.I. \& Wesener, T. (2018) Four new species of giant pill-millipedes from Vietnam (Sphaerotheriida, Zephroniidae). Zootaxa, 4459 (3), 535-550. https://doi.org/10.11646/zootaxa.4459.3.7

Semenyuk, I., Golovatch, S.I. \& Wesener, T. (2020) Some new or poorly-known Zephroniidae (Diplopoda, Sphaerotheriida) from Vietnam. In: Korsós, Z. \& Dányi, L. (Eds.), Proceedings of the $18^{\text {th }}$ International Congress of Myriapodology, Budapest, Hungary. ZooKeys, 930, pp. 37-60. https://doi.org/10.3897/zookeys.930.47742

Shelley, R.M. (2007) Taxonomy of extant Diplopoda (Millipeds) in the modern era: Perspectives for future advancements and observations on the global diplopod community (Arthropoda: Diplopoda). Zootaxa, 1668 (1), 343-362. https://doi.org/10.11646/zootaxa.1668.1.18

Srisonchai, R., Sutcharit, C. \& Likhitrakarn, N. (2021) The giant pill-millipede genus Zephronia Gray, 1832 from Thailand, with a redescription of Z. siamensis Hirst, 1907 and descriptions of three new species (Diplopoda, Sphaerotheriida, Zephroniidae). ZooKeys, 1067, 19-56. https://doi.org/10.3897/zookeys.1067.72369

Tamura, K. \& Nei, M. (1993) Estimation of the number of nucleotide substitutions in the control region of mitochondrial DNA in humans and chimpanzees. Molecular Biology and Evolution, 10, 512-526. https://doi.org/10.1093/oxfordjournals.molbev.a040023

Tamura, K., Stecher, G., Peterson, D., Filipski, A. \& Kumar, S. (2013) MEGA6: Molecular Evolutionary Genetics Analysis Version 6.0. Molecular Biology and Evolution, 30, 2725-2729. https://doi.org/10.1093/molbev/mst197

Tavaré, S. (1986) Some probabilistic and statistical problems in the analysis of DNA sequences. Lectures on mathematics in the life sciences, $17,57-86$.

Verhoeff, KW. (1924) Results of Dr. E. Mjöberg's Swedish scientific expeditions to Australia 1910-1913. Myriapoda, Diplopoda. Arkiv för zoologi, 16 (5), 1-142.

Wesener, T. (2015a) The Giant Pill-Millipedes of Nepal (Diplopoda, Sphaerotheriida, Zephroniidae). Zootaxa, 3964 (3), $301-$ 320. https://doi.org/10.11646/zootaxa.3964.3.1

Wesener, T. (2015b) No millipede endemics north of the Alps? DNA-Barcoding reveals Glomeris malmivaga Verhoeff, 1912 as a synonym of G. ornata Koch, 1847 (Diplopoda, Glomerida, Glomeridae). Zootaxa, 3999 (4), 571-580. https://doi.org/10.11646/zootaxa.3999.4.7

Wesener, T. (2016) The Giant Pill-Millipedes, order Sphaerotheriida - An annotated species catalogue with morphological atlas and list of apomorphies (Arthropoda: Diplopoda). Bonn zoological Bulletin, Supplementum 63, 1-104.

Wesener, T. (2019) First records of giant pill-millipedes from Laos (Diplopoda, Sphaerotheriida, Zephroniidae). Zootaxa, 4563 (2), 201-248. https://doi.org/10.11646/zootaxa.4563.2.1

Wesener, T. \& Anilkumar, P.A. (2020) The millipedes collected by the Museum "La Specola" on Madagascar 1989/1991, with the description of three new species of giant pill-millipedes (Diplopoda, Sphaerotheriida, Arthrosphaeridae). ZooKeys, 930, $3-35$. https://doi.org/10.3897/zookeys.930.47620 
Wesener, T. \& Conrad, C. (2016) Local Hotspots of Endemism or Artifacts of Incorrect Taxonomy? The Status of Microendemic Pill Millipede Species of the Genus Glomeris in Northern Italy (Diplopoda, Glomerida). In: Yue, B.-S. (Ed.), PLoS ONE, 11, e0162284. https://doi.org/10.1371/journal.pone.0162284

Wesener, T. \& Sagorny, C. (2021) Seven new giant pill-millipede species and numerous new records of the genus Zoosphaerium from Madagascar (Diplopoda, Sphaerotheriida, Arthrosphaeridae). European Journal of Taxonomy, 758, 1-48. https://doi.org/10.5852/ejt.2021.758.1423

Wesener, T., Le, D. \& Loria, S. (2014) Integrative revision of the giant pill-millipede genus Sphaeromimus from Madagascar, with the description of seven new species (Diplopoda, Sphaerotheriida, Arthrosphaeridae). ZooKeys, 414, 67-107. https://doi.org/10.3897/zookeys.414.7730

Wesener, T., Wongthamwanich, N. \& Moritz, L. (2021) Description of the first species of Glomeridesmida from Thailand (Diplopoda, Glomeridesmida, Glomeridesmidae). ZooKeys, 1024, 137-156. https://doi.org/10.3897/zookeys.1024.63678

Wongthamwanich, N., Panha, S., Sierwald, P., Wesener, T. \& Thirakhupt, K. (2012) A new species of the giant pill-millipede genus Sphaerobelum Verhoeff, 1924 from northern Thailand, with an extensive description and molecular characters (Diplopoda: Sphaerotheriida: Zephroniidae). Zootaxa, 3220 (1), 29-43. https://doi.org/10.11646/zootaxa.3220.1.2

Zhao, Y., Yu, J. \& Liu, W. (2020) A molecular-based phylogeny of the millipede genus Sphaerobelum Verhoeff, 1924, with the first record of the genus from mainland China (Diplopoda: Sphaerotheriida: Zephroniidae). Annales de la Société entomologique de France, New Series, 56, 341-348. https://doi.org/10.1080/00379271.2020.1811153

\section{SUPPLEMENTAL MATERIAL}

Sup. file 1. Estimates of Evolutionary Divergence between sequences. The number of base differences per site from between sequences are shown. The analysis involved 34 nucleotide sequences. Codon positions included were $1 \mathrm{st}+2 \mathrm{nd}+3 \mathrm{rd}$. All ambiguous positions were removed for each sequence pair. There were a total of 674 positions in the final dataset. Evolutionary analyses were conducted in MEGA6 (Tamura et al. 2013). 